\title{
Heat Transfer Intensification for Retrofitting Heat Exchanger Networks with Considering Exchanger Detailed Performances
}

DOI:

10.1002/aic. 16075

\section{Document Version}

Accepted author manuscript

Link to publication record in Manchester Research Explorer

Citation for published version (APA):

Pan, M., Bulatov, I., \& Smith, R. (2018). Heat Transfer Intensification for Retrofitting Heat Exchanger Networks with Considering Exchanger Detailed Performances. AlChE Journal. https://doi.org/10.1002/aic.16075

\section{Published in:}

AIChE Journal

\section{Citing this paper}

Please note that where the full-text provided on Manchester Research Explorer is the Author Accepted Manuscript or Proof version this may differ from the final Published version. If citing, it is advised that you check and use the publisher's definitive version.

\section{General rights}

Copyright and moral rights for the publications made accessible in the Research Explorer are retained by the authors and/or other copyright owners and it is a condition of accessing publications that users recognise and abide by the legal requirements associated with these rights.

\section{Takedown policy}

If you believe that this document breaches copyright please refer to the University of Manchester's Takedown Procedures [http://man.ac.uk/04Y6Bo] or contact uml.scholarlycommunications@manchester.ac.uk providing relevant details, so we can investigate your claim.

\section{OPEN ACCESS}




\title{
Heat Transfer Intensification for Retrofitting Heat Exchanger Networks with Considering Exchanger Detailed Performances
}

\author{
Ming Pan ${ }^{\mathrm{a}},{ }^{1}$ Igor Bulatov ${ }^{\mathrm{b}}$, and Robin Smith ${ }^{\mathrm{b}}$ \\ ${ }^{a}$ School of Chemical Engineering and Technology, Guangdong Engineering Technology Research Center \\ for Petrochemical Energy Conservation, Sun Yat-Sen University, Guangzhou, 510275, China \\ ${ }^{\mathrm{b}}$ Centre for Process Integration, School of Chemical Engineering and Analytical Science, The University \\ of Manchester, Manchester, M13 9PL, UK
}

The challenging of this work is to present a thorough study of implementing heat transfer intensification in heat exchanger network (HEN) retrofitting, including all details of exchanger geometry, stream bypassing and splitting, temperature-variation of properties, LMTD and its correction, and pressure drops. This leads to very complex mixed integer nonlinear programming (MINLP) problems rarely reported before. By adopting the MILPbased iterative approach proposed in the earlier work (Pan et al. in 2013), temperaturevariation of properties, LMTD and its correction are initialised to parameters at first, and the rest nonlinear terms are then linearised and expressed as first order Taylor series expansions. Finally, two iteration loops are executed to find optimal solutions. A small-scale motivating problem and an industrial scale problem are presented to demonstrate the validity and efficiency of the proposed methods.

Keywords: heat exchanger network (HEN), retrofit, optimisation, mixed integer linear programming (MILP), iteration

\section{Introduction}

Correpondence concerning this article should be addressed to M. Pan at panm5@mail.sysu.edu.cn 
The retrofit of heat exchanger networks (HENs) has received a great deal of attention both in academia and industry, since substantial energy saving can be achieved from various retrofit strategies. ${ }^{1}$ In the early studies, the retrofit approaches widely used included changing exchanger area, installing new heat exchangers, and modifying network topology (e.g. repiping stream and rearranging heat-recovery matches). However, implementing network topology modifications often leads to high retrofit costs. High costs arise not just from the installation of new equipment, but the consequent impact of changes on the rest of the network requiring changes in heat exchanger area.

Intensified heat transfer techniques are one way to overcome these problems. Existing heat exchangers can be made to work more effectively through increasing heat transfer coefficients, lowering not only equipment costs, but the cost of piping modifications and civil engineering. ${ }^{2-4}$ To intensify heat transfer in shell-and-tube heat exchangers, several options are available. For tube-side enhancements, twisted-tape inserts, coiled-wire inserts, and mesh inserts (e.g. hiTRAN ${ }^{\circledR}$ ) can be used. For shell-side enhancements, segmental baffles, helical baffles, and EM baffles ${ }^{\circledR}$ can be used. ${ }^{5}$ Tube inserts are easily installed and removed and disrupt the flow in the tube side to increase its heat transfer coefficient. For shell-side enhancements in this paper, the shell-side geometry of an exchanger can be changed (such as reducing baffle spacing) to increase the shell-side flow velocity and heat transfer coefficient.

Two types of design approaches have been commonly used for HEN retrofit: thermodynamic-mathematical programming methods and completely mathematical programming methods. Most of the thermodynamic-mathematical programming methods are based on the pinch concept. In these studies, several efficient alternative networks are found based on Pinch Analysis, and mathematical programming techniques are then used to select the network requiring the minimum capital cost. Asante and Zhu have proposed a series of work to address HEN retrofit problems which consisted of a diagnosis stage (network pinch) 
and an optimisation stage. Suitable modification options were selected in the first stage and then optimised in the existing HEN. ${ }^{6-7}$ For heat transfer enhancement, Nie and Zhu integrated the network pinch and mathematical programming method to treat the exchangers, with and without additional area, and then calculated their accurate pressure drops. ${ }^{8}$ In addition, some pinch methods can be applied without using mathematical programming. Li and Chang proposed a simple pinch analysis approach, to modify the cross-pinch matches and utilise the existing exchangers as much as possible to keep a reasonably low capital investment. ${ }^{9}$ Nordman and Berntson presented new insights about the complexity and possible solutions of different retrofit alternatives. ${ }^{10}$ They stated that if the existing heaters/coolers are placed closer to the pinch, more cost-effective retrofit can be achieved. Besides pinch analysis approaches, heuristic methods have been reported to successfully solve large-scale industrial problems. Gadalla proposed a method for HEN retrofit based on a graph by plotting temperatures of process hot streams versus temperatures of process cold streams. ${ }^{11}$ This graphical representation can easily identify exchangers across the pinch, the Network Pinch, pinching matches and improper placement of energy consumption. Recently, Bonhivers et al. combined pinch analysis and bridge analysis into a consistent method for HEN retrofit. ${ }^{12}$ In their work, the Energy Transfer Diagram and the Heat Exchanger Load Diagram were used to describe the relations between the composite curves of an existing HEN, and then pinch analysis with the developed bridge analysis can help to identify supplementary solutions to save energy.

To achieve completely automated optimisation, other researchers have used mathematical programming methods. Most of the reported HEN retrofit problems are described as MINLP formulations or NLP-MILP combination formulations. Floudas et al. proposed an automatic procedure based on mathematical programming approach for HEN configurations. ${ }^{13}$ In their work, a HEN superstructure was derived by a mixed integer linear programming (MILP) 
transhipment model, and the network configuration was generated by minimizing the investment cost of the superstructure through a nonlinear programming (NLP) formulation. Akman et al. proposed a simple 1-1 shell-and-tube heat exchanger model (LMTD-free model) for HEN optimisations. ${ }^{14}$ Their proposed model can avoid the computational difficulties associated with using the nonlinear term of logarithmic mean temperature difference (LMTD). Silva and Zemp addressed changeable heat transfer coefficients and pressure drops for HEN retrofit. ${ }^{15}$ They formulated the retrofit problem as a nonlinear model, and estimated additional exchanger area and pressure drops based on economic optimisation. Other optimisation algorithms have been developed for HEN retrofit, such as genetic algorithms (GA) ${ }^{16-19}$, simulated annealing (SA) ${ }^{20,21}$ and constraint logic programming (CLP) ${ }^{22}$. Although these algorithms are efficient in some specified retrofit situations, they still suffer from the combinatorial complexity of large HEN problems. Recently, the MILP approach has become an attractive approach from a computational standpoint. It is a great challenge to completely formulate HEN problems without any simplifying assumptions. ${ }^{23}$ Nguyen et al. presented a new MILP method for HEN synthesis and retrofit, which can easily provide suboptimal solutions by identifying intermediate feasible solutions or excluding the current optimal solution. ${ }^{24}$ Pan et al. proposed a novel iterative MILP-based method for HEN retrofit with heat transfer intensification. ${ }^{25}, 26$ Their automated design method was proposed to systematically consider heat transfer enhancement for retrofitting HENs.

Multi-objective optimisation, flexibility and controllability have also been regarded as the important features of HEN retrofitting in the recent work. Sreepathi and Rangaiah compared single objective optimisation and multi-objective optimisation in some HEN retrofit scenarios, such as exchanger reassignment, and variable stream specific heat capacities. ${ }^{27,28}$ They found that their Pareto-optimal front obtained from multi-objective optimisation had many optimal solutions, which provided even more optimal solutions for evaluation and selection for 
implementation. Escobar et al. ${ }^{29}$ presented a computational framework (SYNFLEX) based on two-stage strategy of multi-period design oriented to the SYNHEAT model ${ }^{30}$ for the automatic generation of flexible designs. Then, they proposed a framework yielding a HEN design, which was guaranteed to operate with the designed control system under varying conditions, ensuring stream temperature targets and optimal energy integration. ${ }^{31}$

Based on the above discussion, the nonlinearities of HEN retrofit problems lead to the computational complexity using mathematical programming methods. In most industrial cases, HEN retrofit problems are formulated as large-scale MINLP models, and it is difficult to obtain optimal solutions using traditional methods. Some researchers used approximate LMTD functions to reduce model complexities, which might underestimate or overestimate the driving force if the temperature difference approach between exchanger hot side and cold side is significantly large or small. ${ }^{32-35}$ Some researchers proposed a LMTD-free model based on dynamic analysis. ${ }^{14}$ But their partial-differential-equation model only described the counter-current heat transfer in a specified type of exchanger (namely 1-1 shell-and-tube heat exchanger), which limits its application to other exchanger types (multiple tube passes and shell passes). To convert MINLP problems to MILP problems, some researchers defined several heat transfer zones, and divided these zones to several fixed temperature intervals, thus the LMTD in each interval was known and constant. ${ }^{24}$ However, due to the combinatorial complexity of such MILP models, the number of binary variables increases significantly when more intervals and process streams are considered, and the problems become larger and difficult to solve.

Unlike the approaches mentioned above, the methods proposed by the authors in previous papers can avoid the computational difficulties without using any simplifying assumptions and approximate functions, and find optimal solutions effectively ${ }^{4,21,23 \text { and } 26}$. However, these methods are only suitable for special HEN retrofit scenarios, such as only tube-side geometry 
changes ${ }^{4}$, constant stream specific heat capacities ${ }^{21}$, no exchanger geometry changes ${ }^{23}$, and no stream bypassing and splitting ${ }^{26}$. The novelty of this work is that it is the first study to address the comprehensive HEN retrofit problem with exchanger detailed performances, which includes the actual calculations for LMTD and LMTD correction factor $\left(\mathrm{F}_{\mathrm{T}}\right)$, the tubeside and shell-side geometry details for heat transfer coefficients and pressure drops, multiple tube passes and shell passes, added/reduced exchanger area, new exchanger installation, pressure drop constraints, stream bypassing and splitting, and the temperature dependence of stream specific heat capacities (CPs). To deal with the computational difficulties caused by the above retrofit features, an efficient optimisation approach is proposed. Firstly, the problems of retrofitting HENs with all potential strategies are formulated. LMTD, $\mathrm{F}_{\mathrm{T}}$ and the temperature dependence of CPs are defined and initialised based on the initial HEN. The other nonlinear terms are linearised by using the first order Taylor series expansions. Finally, the HEN retrofit problem can be expressed as a complete MILP model, and two iteration loops are developed to find optimal solutions.

The rest of this paper is structured as follows: a detailed problem statement is introduced in the next section, which is then followed by a motivating example to highlight the advantages of the new work through the comparison of the new and traditional retrofit approaches. HEN retrofit is then formulated as a new MILP model based on a series of linearisation strategies. Later, two loops are proposed to solve the MILP model iteratively to achieve optimal retrofit. Finally, two examples are used to demonstrate the validity and efficiency of the new method.

\section{Problem Statement}

In this paper, shell-and-tube heat exchangers, the most widely used exchangers in process industries, can be enhanced through several intensification techniques, such as implementing 
tube inserts and changing tube passes (tube-side intensification), and reducing baffle spacing (shell-side intensification). Generally, the available strategies of retrofitting HEN without topology modification include enhancing tube-side and shell-side heat transfer, adding/reducing exchanger area, installing new heat exchangers in series (increasing shell passes), and implementing bypass streams. ${ }^{36}$ In addition, implementing the above retrofit strategies must satisfy the restriction of maximum pump duty in the existing HENs. Thus, the problem addressed in this paper is based on the following statement.

It is assumed that the following information is given:

(1) Matches between hot streams and cold streams (the existing network topology).

(2) Status of the existing HEN (i.e. the initial stream temperatures and flow rates in each exchanger, and the initial geometry details of exchangers).

(3) Exchanger mathematical expressions (i.e. formulations of heat transfer coefficients and pressure drops based on exchanger geometry and temperatures).

(4) Stream data (i.e. maximum pump duties, flowrates, inlet and outlet temperatures, temperature dependence of CPs and fouling coefficients).

(5) Economic data (i.e. utility costs, and costs for retrofit strategies).

(6) Model parameters are all known and unchanged during the retrofit procedure.

An optimisation methodology for retrofitting HEN is required:

(1) To identify suitable heat exchangers for retrofit.

(2) To implement one or more retrofit techniques (enhancing tube-side and shell-side heat transfer, increasing shell passes and implementing stream bypassing) in the selected heat exchangers. 
(3) To replace an existing exchanger with a new one, if the existing exchanger requires less or more heat transfer area (namely changing exchanger length) in this work.

(4) To calculate the heat transfer coefficients and pressure drops of exchangers in the retrofitted HEN.

(5) To calculate accurate LMTD for each exchanger in the retrofitted HEN.

(6) To calculate accurate $\mathrm{F}_{\mathrm{T}}$ for each exchanger in the retrofitted HEN.

(7) To satisfy the restrictions on heat transfer and energy balance in each exchanger.

(8) To satisfy the pressure drop restrictions for the HEN topology by exploiting parallel exchangers and bypass streams.

(9) To satisfy the restriction of total pump duty for each stream.

(10) To calculate the costs for all retrofit strategies.

The objective is the maximisation of retrofit profit. Figure 1 shows an illustration of using the proposed approach for HEN retrofitting. Moreover, the following assumptions are made based on the practical retrofit procedure:

(1) Segmental shell-and-tube exchangers are used in the HEN. So far, the most common and widely-used exchanger models are based on segmental baffles. To improve shellside heat transfer, heat exchanger types other than segmental baffles (e.g. helical baffles, EM baffles ${ }^{\circledR}$ ) will be considered in future work.

(2) Some geometry details of shell-and-tube heat exchangers are constant in the practical retrofit procedure, including tube inner and outer diameters, number of tubes, tube bundle, tube pitch, tube layout angle, shell diameter, baffle cut, and tube wall conductivity. Exchanger length, tube insert density, tube passes, baffle spacing, and flow rates can be used to modify an existing exchanger. 
(3) Based on Assumption 2, tube-side heat transfer coefficient and pressure drop correlate with tube-side flow rate, tube-side stream average temperature, tube insert density, tube passes, and exchanger length, and their correlations are nonlinear.

(4) Similar to the nonlinear correlations in tube side, shell-side heat transfer coefficient and pressure drop correlate with shell-side flow rate, shell-side stream average temperature, baffle spacing, and exchanger length.

(5) The relocation of existing exchangers is not addressed in this work. Once an existing exchanger is relocated, the stream properties on its tube/shell or both sides will change. This leads to very complicated calculations for exchanger heat transfer coefficients and pressure drops, and increases the difficulty of solving HEN retrofitting problems. To avoid this, we propose implementing intensification techniques in the retrofitted exchangers or using a new exchanger, rather than relocating an existing exchanger.

(6) Changing area of existing exchangers is not considered in this work. In practice, area of existing shell-and-tube exchangers can be reduced within certain limits, for instance, blocking some tubes to reduce the overall area of an exchanger. However, this is restricted by the maximum allowed tube-side pressure drop of the exchanger, as blocking tubes will increase the tube-side flow rate and may lead to a serious vibration problem.

\section{Motivating Example}

A literature example is presented in this section to provide some new insights into the practical application of HEN retrofitting, then illustrate the complexity of the problem addressed, and highlight the drawbacks that the existing approaches may suffer from. Based on the literature review in the introduction section, most of the existing approaches assumed 
constant heat transfer coefficients in exchangers, and neglected pressure drop restrictions. These may lead to unrealistic retrofit solutions, as the heat transfer coefficients and pressure drops commonly change with stream properties and exchanger geometry. Figure 2 shows an example of HEN retrofitting with a conventional approach. ${ }^{9}$ This example assumes constant stream CPs (the heat-flow capacity of each stream is $228.5 \mathrm{~kW} / \mathrm{K}(\mathrm{S} 1), 20.4 \mathrm{~kW} / \mathrm{K}$ (S2), 53.8 $\mathrm{kW} / \mathrm{K}(\mathrm{S} 3), 93.3 \mathrm{~kW} / \mathrm{K}(\mathrm{S} 4)$, and $196.1 \mathrm{~kW} / \mathrm{K}(\mathrm{S} 5))$, which implies constant heat transfer coefficients. In Figure 2 (b), it can be found that $5186 \mathrm{~kW}$ is reduced from the hot utility and cold utility by relocating some existing exchangers (Exchangers 3 and 4) and adding one new exchanger (Exchanger 5). However, when the practical issues are considered, such as $\mathrm{F}_{\mathrm{T}}$, temperature dependence of stream CPs, variable heat transfer coefficients, and pressure constraints, the conventional approach is not capable of solving this problem.

To consider the practical issues for this motivating example, the following information is given in detail:

(1) The flow rate of each stream is: $47.6 \mathrm{~kg} / \mathrm{s}(\mathrm{S} 1), 10.2 \mathrm{~kg} / \mathrm{s}(\mathrm{S} 2), 21.5 \mathrm{~kg} / \mathrm{s}(\mathrm{S} 3), 31.1$ $\mathrm{kg} / \mathrm{s}(\mathrm{S} 4), 49 \mathrm{~kg} / \mathrm{s}$ (S5), and 50kg/s (all utility streams).

(2) $300 \mathrm{kPa}$ of maximum pump duty is restricted in each process stream.

(3) The stream specific heat $(C P)$ in an exchanger is expressed as a linear relationship with the stream average temperature:

$C P=A_{C P} \times T_{\text {stream }}^{\text {ave }}-B_{C P}$

where $T_{\text {stream }}^{\text {ave }}$ is stream average temperature on tube or shell side in an exchanger, $A_{C P}$ and $B_{C P}$ are parameters to calculate temperature dependence of $C P$ (as shown in Table $1)$.

(4) Based on the Assumptions (3) and (4) mentioned in the Problem Statement and the detailed exchanger models proposed by Wang et al. ${ }^{2}$ and Pan et al. ${ }^{5}$, the heat transfer coefficients and pressure drops in the tube-side and shell-side of an exchanger 
(assumed that hot fluid is in the shell side, and cold fluid is in the tube side) can be regressed in Eqs. 2-7.

$h_{i}^{-1}=A_{h i} \times\left(F R_{i} \times n_{p}\right)^{-0.4} \times e^{-0.007 i_{i}^{a v e}} \quad$ without tube inserts

$h_{i e}^{-1}=A_{\text {hie }} \times\left(F R_{i} \times n_{p}\right)^{-0.6} \times e^{-0.00 T_{i}^{\text {ave }}} \times \rho_{\text {insert }}^{-1.0392}$ with tube inserts

$h_{0}^{-1}=A_{h 0} \times F R_{0}^{-0.35} \times e^{-0.006 T_{0}^{a v e}} \times B S^{1.4444}$

$\Delta P_{i}=A_{p i} \times\left(F R_{i} \times n_{p}\right)^{1.7415} \times e^{-0.003 T_{i}^{a v e}} \times L \quad$ without tube inserts

$\Delta P_{i e}=A_{\text {pie }} \times\left(F R_{i} \times n_{p}\right)^{1.85} \times e^{-0.003 T_{i}^{\text {ave }}} \times L \times\left(2072.73-33.82 \rho+\rho^{2}\right)$

$\Delta P_{0}=A_{p 0} \times F R_{0}^{1.322} \times e^{-0.0045 T_{0}^{\text {ave }}} \times L \times\left(0.179+0.041 B S-B S^{2}\right)$

where $E X$ is the set of all exchangers, $h_{i}, h_{i e}, \Delta P_{i}$ and $\Delta P_{i e}$ are the heat transfer coefficients and pressure drops in the tube side without/with tube inserts, $h_{0}$ and $\Delta P_{0}$ are the heat transfer coefficients and pressure drops in the shell side, $\rho$ is tube-insert density, $B S$ is baffle spacing, $L$ is exchanger length, $n_{p}$ is tube pass, $T_{i}^{\text {ave }}$ and $T_{0}^{\text {ave }}$ are the stream average temperatures in tube side and shell side, $F R_{i}$ and $F R_{0}$ are the flow rates in tube side and shell side. Table 2 presents the parameters $\left(A_{h i}, A_{h i e}, A_{h o}, A_{p i}, A_{p i e}\right.$ and $A_{p 0}$ ) for the calculation of $h_{i}, h_{i e}, h_{0}, \Delta P_{i}, \Delta P_{i e}$ and $\Delta P_{0}$. These parameters are valid for specific types of exchangers. Different geometry details of exchangers have different parameters. In this work, heat exchange between streams without phase change (i.e., heat exchange between gas streams, between liquid and gas streams, and between liquid streams) is used for heat exchanger model. But it does not restrict the proposed approach to be implemented for the HEN retrofit in which phase change can occur in the exchanger, as long as the performance of the exchanger can be evaluated through mathematical modelling or performance data.

(5) The functions of retrofit costing are assumed as several linear correlations: ${ }^{37}$ 


$$
\begin{aligned}
& C R L_{e x}=F C R L_{e x}+P C R L_{e x} \times E X A_{e x}, \quad \forall e x \in E X \\
& C I L_{e x}=F C I L_{e x}+P C I L_{e x} \times E X A_{e x}, \quad \forall e x \in E X \\
& C T E_{e x}=F C T E_{e x}+P C T E_{e x} \times E X A_{e x}, \quad \forall e x \in E X \\
& C T P=F C T P \times N T P \\
& C B S=F C B S \times N B S \\
& C B P=F C B P \times N B P
\end{aligned}
$$

where $C R L_{e x}$ and $C I L_{e x}$ are the costs of reducing and increasing exchanger length (namely installing new exchanger), $C T E_{e x}$ is the cost implementing tube inserts in exchanger ex, $C T P, C B S$ and $C B P$ are the costs of changing tube passes, baffle spacing and stream bypassing, $F C R L_{e x}, F C I L_{e x}, F C T E_{e x}, F C T P, F C B S$ and $F C B P$ are the fixed costs for retrofit implementations, $P C R L_{e x}, P C I L_{e x}$ and $P C T E_{e x}$ are the variable costs related to exchanger area, and $N T P, N B S$ and $N B P$ are the numbers of exchangers with changed tube passes, baffle spacing and stream bypassing. The cost parameters used in this example are $F C R L_{e x}=2000(\$), P C R L_{e x}=100\left(\$ / \mathrm{m}^{2}\right), F C I L_{e x}$ $=2000(\$), P C I L_{e x}=100\left(\$ / \mathrm{m}^{2}\right), F C T E_{e x}=500(\$), P C T E_{e x}=10\left(\$ / \mathrm{m}^{2}\right), F C T P=500$ $(\$), F C B S=300(\$)$, and $F C B P=500(\$)$.

(6) Commonly, the flow pattern in multi-pass types includes both counter and co-current flows, so the mean temperature difference of a heat exchange is not equal to LMTD, and a correction factor of LMTD $\left(\mathrm{F}_{\mathrm{T}}\right)$ is required to correct the discrepancy. The $\mathrm{F}_{\mathrm{T}}$ formulations introduced by $\operatorname{Serth}^{38}$ are adopted for any number of shell-side passes and any even number of tube-side passes.

$$
\begin{array}{cc}
R_{e x}=\frac{H T I_{e x}-H T O_{e x}}{C T O_{e x}-C T I_{e x}}, & \forall e x \in E X, \\
P_{e x}=\frac{C T O_{e x}-C T I_{e x}}{H T I_{e x}-C T I_{e x}}, & \forall e x \in E X,
\end{array}
$$


If $R_{e x} \neq 1$ :

$$
\begin{aligned}
& \alpha_{e x}=\left(\frac{1-R_{e x} \times P_{e x}}{1-P_{e x}}\right)^{1 / N S P_{e x}}, \quad \forall e x \in E X \\
& S_{e x}=\frac{\alpha_{e x}-1}{\alpha_{e x}-R_{e x}}, \quad \forall e x \in E X \\
& F T_{e x}=\frac{\sqrt{R_{e x}^{2}+1 \times \ln \left(\frac{1-S_{e x}}{1-R_{e x} \times S_{e x}}\right)}}{\left(R_{e x}-1\right) \times \ln \left[\frac{2-S_{e x} \times\left(R_{e x}+1-\sqrt{R_{e x}^{2}+1}\right)}{2-S_{e x} \times\left(R_{e x}+1+\sqrt{R_{e x}^{2}+1}\right)}\right]} \quad \forall e x \in E X
\end{aligned}
$$

If $R_{e x}=1$ :

$$
\begin{aligned}
& S_{e x}=\frac{P_{e x}}{N S P_{e x}-\left(N S P_{e x}-1\right) P_{e x}}, \quad \forall e x \in E X \\
& F T_{e x}=\frac{\sqrt{2} S_{e x}}{\left(1-S_{e x}\right) \times \ln \left[\frac{2-S_{e x} \times(2-\sqrt{2})}{2-S_{e x} \times(2+\sqrt{2})}\right]}, \quad \forall e x \in E X
\end{aligned}
$$

In Eqs. 14-20, $H T I_{e x}$ and $C T I_{e x}$ are inlet temperatures for the hot and cold streams in exchanger ex, $H T O_{e x}$ and $C T O_{e x}$ are outlet temperatures of hot and cold streams in exchanger $e x, F_{T e x}$ is the $\mathrm{F}_{\mathrm{T}}$ value of exchanger $e x, N S P_{e x}$ is the number of shell passes in exchanger $e x$, and $R_{e x}, P_{e x}, \alpha_{e x}$ and $S_{e x}$ are the factors used to calculate $\mathrm{F}_{\mathrm{T}}$ in exchanger $e x$.

(7) The retrofit profit $(R P)$ can be calculated as the profit of reducing energy consumption (PES) minus the total retrofitting costs. 
$P E S=Y R \times\left\{C C U \times \sum_{e x \in E X_{h u}}\left[C F C P_{e x} \times\left(C T I_{e x}-O C T I_{e x}\right)\right]+C H U \times \sum_{e x \in E X_{c u}}\left[H F C P_{e x} \times\left(O H T I_{e x}-H T I_{e x}\right)\right]\right\}$

where $C C U$ is a yearly cost parameter per cold-utility-duty unit, $C H U$ is a yearly cost parameter per hot-utility-duty unit, $E X_{h u}$ and $E X_{c u}$ are the set of all exchangers consuming hot and cold utilities, $C F C P_{e x}$ and $H F C P_{e x}$ are the heat-flow capacities (the multiplication between heat capacity and flow-rate) of cold and hot streams in exchanger ex, $O H T I_{e x}$ and $O C T I_{e x}$ are the inlet temperatures of hot and cold streams in exchanger ex in the original HEN, and $Y R$ is the expected project lifetime.

Thus, the retrofit profit before tax accumulated over the expected lifetime $(R P)$ of the retrofitted HEN is obtained:

$$
R P=P E S-\sum_{e x \in E X}\left(C R L_{e x}+C I L_{e x}+C T E_{e x}\right)-(C T P+C B S+C B P)
$$

In this motivating example, $C C U=0(\$ / \mathrm{kW} \cdot$ year $)$, and $C H U=100(\$ / \mathrm{kW} \cdot$ year $)$. The expected project lifetime $(Y R)$ is set as one year for total profit calculation. This simple example under the project lifetime of one year is carried out to demonstrate that the new model can achieve higher profit comparing to the conventional models. It does not restrict the proposed approach to be used in a longer project lifetime.

(8) By implementing heat transfer intensification techniques in shell-and-tube heat exchangers, very high heat transfer coefficients can be achieved, and thus the minimum approach temperature is set to $5{ }^{\circ} \mathrm{C}$ for each intensified exchanger after HEN retrofit ${ }^{39}$.

The objective of retrofitting the HEN is to increase the energy saving and maximize the retrofit profit. As described above, more details in exchanger geometry and stream property are addressed in the practical HEN retrofit procedure, such as temperature dependence of 
stream CPs, stream and exchanger geometry dependence of heat transfer coefficients and pressure drops, and LMTD correction factor $\left(\mathrm{F}_{\mathrm{T}}\right)$ associated with multiple tube passes and shell passes. The existing approaches cannot predict the detailed performance of each exchanger in such complex retrofit scenario, thus limiting their applications. Our new optimisation method can improve the energy efficiency of the motivating example with implementing the techniques of heat transfer intensification, as presented in Figure 3. Tables 3 and 4 show the detailed exchanger performances and retrofit costs in the original and retrofitted networks given by the new approach in the complex retrofit scenarios. It is noted that, more practical HEN retrofitting features can be found in this work compared with the conventional retrofit approaches:

- The performance of an exchanger is affected by its geometry details, such as exchanger length, tube and shell passes, fluid flow rates, baffles spacing, and tubeinsert density.

- The pressure drops in the same parallel exchanger group must be identical, for instance, the tube-side pressure drops of Exchangers 1 and 4 are $2.6 \mathrm{kPa}$, and the tube side pressure drops of Exchangers 2 and 3 are $2.4 \mathrm{kPa}$, as shown in Figure 3 (c) and Table 3. It can be noted that the pressure drops of 2.6 and $2.4 \mathrm{kPa}$ are low. Based on Eqs. 5 and 6, flowrate $\left(F R_{i}\right)$ and tube pass $\left(n_{p}\right)$ are the main factors affecting pressure drop. Thus, reducing these two factors significantly after retrofit usually lead to low tube-side pressure drops in Exchangers 1-4 (see the solution of Retrofitted HEN with topology modification in Table 3).

- As shown in Table 4, the restrictions of total pressure drop are satisfied in each process stream (300 $\mathrm{kPa}$ of maximum pump duty restricted in each process stream). The pressure drops of some streams increase (such as $258.3 \%$ in S1, 260.1\% in S2, and $251.1 \%$ in S3) due to heat transfer enhancements. 
- When the $\mathrm{F}_{\mathrm{T}}$ of an exchanger is less than 0.8 or infeasible, single tube pass must be set. $^{38}$ Thus, Exchangers 1, 3 and 4 in Figure 3 (b) and Exchangers 2 and 4 in Figure 3 (c) are required to reduce multiple tube passes to the single pass because of their $F_{T}$ inefficiency.

- According to the item (8) assumed for the motivating example, different minimum approach temperatures are used for the exchangers with and without intensification: $\Delta T_{\min }=5^{\circ} \mathrm{C}$ (with tube inserts) and $\Delta T_{\min }=19^{\circ} \mathrm{C}$ (without tube inserts). In Figure 3(b), the minimum approach temperatures of the intensified exchangers 1, 3 and 4 are $5{ }^{\circ} \mathrm{C}$, and the minimum approach temperatures of the non-intensified exchangers $(2$, $\mathrm{C} 1, \mathrm{C} 2$ and $\mathrm{H})$ are $19^{\circ} \mathrm{C}$. While in Figure 3(c), the minimum approach temperatures of all exchangers are $19{ }^{\circ} \mathrm{C}$ as no intensification is implemented. The solution of retrofitting HEN with intensified exchangers (Figure 3 (b)) requires lower minimum approach temperature and thus can achieve more energy saving compared with the topology modification proposed in Figure 3 (c), leading to a higher retrofit profit (\$310060 vs. \$92679, as shown in Table 4).

Although the conventional approaches, proposing network topology modifications for HEN retrofit, have been reported to be effective for solving many simple examples, their solutions are still not suitable for practical applications, as they neglect HEN changes related to exchanger geometry details and stream properties. Furthermore, it would be difficult to estimate capital investments caused by network structural modification and exchanger rearrangement, because of a significant amount of piping and civil work might be required for the retrofit and uncertain potential production losses during the retrofit. In the rest of this paper, the new optimisation approach is introduced to address exchanger details and implement intensified heat transfer (tube inserts) for improving the energy efficiency of complex HENs. 


\section{New HEN Retrofit Model}

As mentioned in the Problem Statement, a large number of nonlinear terms associated with LMTD, $\mathrm{F}_{\mathrm{T}}$, heat transfer coefficients, pressure drops, heat transfer and energy balances, have to be addressed for formulating HEN retrofit problems. These nonlinear terms lead to a complex non-convex MINLP problem involving logarithmic equations, exponential equations, power equations, bilinear equations, and polynomial equations. The efficient MILP-based iteration strategy proposed in our previous work ${ }^{23}$ is adopted to overcome the computational difficulty associated to the above nonlinear equations. First of all, the temperature-related variables $\left(\mathrm{LMTD}, \mathrm{F}_{\mathrm{T}}\right.$ and $\mathrm{CP}$ ) are initialised based on the initial temperatures in an existing HEN, and then the rest nonlinear correlations are described as the first order Taylor series expansions. Some variables for the new model details are illustrated in Figure 4 to make the model readily understandable. These variables include network temperatures, stream temperatures, exchanger temperatures, and the temperatures before and after bypass streams.

\section{Initialising temperature related variables to parameters}

Exchanger temperatures are the decision variables in the optimization, but lead to very complex nonlinear equations for calculating $L M T D, L M T D$ correction factor and stream CP. To avoid such nonlinearity, these temperature-related variables are initialised to parameters. Their values will be updated iteratively in the iteration algorithm after the MILP problem is solved ${ }^{23}$.

Initial logarithmic mean temperature difference (LMTD') 
To convert the logarithmic term to be a parameter, the initial $L M T D_{e x}\left(L M T D_{e x}{ }^{\prime}\right)$ is proposed based on the stream initial temperatures $\left(H T I_{e x}^{\prime}, H T O_{e x}^{\prime}, C T I_{e x}^{\prime}\right.$ and $\left.C T O^{\prime}{ }_{e x}\right)$ in the original HEN, as shown in Eq. 23.

$L M T D_{e x}^{\prime}=\frac{\left(H T I_{e x}^{\prime}-C T O_{e x}^{\prime}\right)-\left(H T O_{e x}^{\prime}-C T I_{e x}^{\prime}\right)}{\ln \left[\left(H T I_{e x}^{\prime}-C T O_{e x}^{\prime}\right) /\left(H T O_{e x}^{\prime}-C T I_{e x}^{\prime}\right)\right]}, \quad \forall e x \in E X$

Initial LMTD correction factor $\left(F_{T}\right)$

According to Eqs. 14-20, the LMTD correction factor $\left(F_{T}\right)$ also can be fixed as a parameter in the MILP model, the same with $L M T D_{e x}$ '.

$R_{e x}^{\prime}=\frac{H T I_{e x}^{\prime}-H T O_{e x}^{\prime}}{C T O_{e x}^{\prime}-C T I_{e x}^{\prime}}, \quad \forall e x \in E X$

$P_{e x}^{\prime}=\frac{C T O_{e x}^{\prime}-C T I_{e x}^{\prime}}{H T I_{e x}^{\prime}-C T I_{e x}^{\prime}}, \quad \forall e x \in E X$

If $R_{e x}^{\prime} \neq 1$ :

$$
\begin{aligned}
& \alpha_{e x}^{\prime}=\left(\frac{1-R_{e x}^{\prime} \times P_{e x}^{\prime}}{1-P_{e x}^{\prime}}\right)^{1 / N S P_{e x}^{\prime}}, \quad \forall e x \in E X \\
& S_{e x}^{\prime}=\frac{\alpha_{e x}^{\prime}-1}{\alpha_{e x}^{\prime}-R_{e x}^{\prime}}, \quad \forall e x \in E X \\
& F T_{e x}^{\prime}=\frac{\sqrt{R_{e x}^{\prime 2}+1} \times \ln \left(\frac{1-S_{e x}^{\prime}}{1-R_{e x}^{\prime} \times S_{e x}^{\prime}}\right)}{\left(R_{e x}^{\prime}-1\right) \times \ln \left[\frac{2-S_{e x}^{\prime} \times\left(R_{e x}^{\prime}+1-\sqrt{R_{e x}^{\prime 2}+1}\right)}{2-S_{e x}^{\prime} \times\left(R_{e x}^{\prime}+1+\sqrt{R_{e x}^{\prime 2}+1}\right)}\right]} \quad \forall e x \in E X
\end{aligned}
$$


If $R_{e x}^{\prime}=1$ :

$$
\begin{aligned}
& S_{e x}^{\prime}=\frac{P_{e x}^{\prime}}{N S P_{e x}^{\prime}-\left(N S P_{e x}^{\prime}-1\right) P_{e x}^{\prime}}, \quad \forall e x \in E X \\
& F T_{e x}^{\prime}=\frac{\sqrt{2} S_{e x}^{\prime}}{\left(1-S_{e x}^{\prime}\right) \times \ln \left[\frac{2-S_{e x}^{\prime} \times(2-\sqrt{2})}{2-S_{e x}^{\prime} \times(2+\sqrt{2})}\right]}, \quad \forall e x \in E X
\end{aligned}
$$

\section{Initial stream CPS}

It is sometimes unrealistic to assume constant stream $\mathrm{CP}$ during the retrofit procedure, as the stream CP is commonly temperature-dependent. Some researchers divided streams into a series of segments with constant $\mathrm{CP}$, so the variation in the specific heat capacity of the stream was approximated by piecewise constant specific heat capacities. ${ }^{7}$ However, this method is not suitable for the situation when some exchangers in the network are located across more than one segment.

In this paper, stream CPs are initialised based on the stream initial temperatures, and can be set as parameters in the MILP model. Eqs. 31-35 describe the specific heat capacities for all stream addressed in this paper, including the hot stream $\mathrm{CP}$ in exchanger $e x\left(H C P^{\prime}{ }_{e x}\right)$, the cold stream $\mathrm{CP}$ in exchanger ex $\left(C C P^{\prime}{ }_{e x}\right)$, the $\mathrm{CP}$ of bypass stream $s$ in exchanger $e x$ $\left(S B C P{ }_{s, e x}\right)$, the $\mathrm{CP}$ of stream $s$ in exchanger ex $\left(S C P{ }_{s, e x}\right)$, and the CP of stream $s$ in parallel exchanger ex $\left(\operatorname{PSCP}_{s, e x}\right)$. The functions of these stream specific heat capacities $\left(f_{H C P_{e x}}()\right.$,

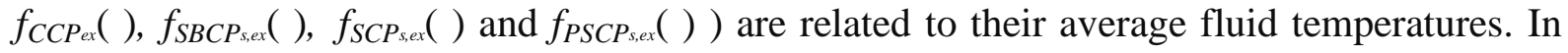
addition, $P E X$ is the set of all parallel exchangers, $S$ is the set of all streams, $S T I_{s, e x}$ and $S T O_{s, e x}$ are stream temperatures in exchanger ex before and after mixed with bypass stream $s$, and $P S T O{ }_{s, e x}^{\prime}$ is the temperature of mixed streams after parallel exchangers in stream $s$. 


$$
\begin{aligned}
& H C P_{e x}^{\prime}=f_{H C P_{e x}}\left(\frac{H T I_{e x}^{\prime}+H T O_{e x}^{\prime}}{2}\right), \quad \forall e x \in E X \\
& C C P_{e x}^{\prime}=f_{C C P_{e x}}\left(\frac{C T I_{e x}^{\prime}+C T O_{e x}^{\prime}}{2}\right), \quad \forall e x \in E X \\
& S B C P_{s, e x}^{\prime}=f_{S B C P_{s, e x}}\left(\frac{S T I_{s, e x}^{\prime}+S T O_{s, e x}^{\prime}}{2}\right), \quad \forall e x \in E X, \quad s \in S \\
& S C P_{s, e x}^{\prime}=\left\{\begin{array}{ll}
f_{S C P_{s, e x}\left(\frac{C T O_{e x}^{\prime}+S T O_{s, e x}^{\prime}}{2}\right)} & \text { if } s \text { is cold stream } \\
f_{S C P_{s, e x}\left(\frac{H T O_{e x}^{\prime}+S T O_{s, e x}^{\prime}}{2}\right)} & \text { if } s \text { is hot stream }
\end{array}, \quad \forall e x \in E X, \quad s \in S\right. \\
& P S C P_{s, e x}^{\prime}=f_{P S C P_{s, e x}}\left(\frac{S T O_{s, e x}^{\prime}+P S T O_{s, e x}^{\prime}}{2}\right), \quad \forall e x \in P E X, \quad s \in S
\end{aligned}
$$

\section{First order Taylor series expansions for the rest nonlinear correlations}

Besides LMTD, $\mathrm{F}_{\mathrm{T}}$ and stream $\mathrm{CP}$, the correlations of heat transfer coefficients, pressure drops, heat transfer and energy balances are also nonlinear in HEN retrofitting problems. To linearise these correlations, first order Taylor series expansion is proposed. Eqs. 36-38 are the representative equations for such conversion, where $y$ is a variable, $f(X)$ is a nonlinear function, $X$ is the set of variables in $f(X), X^{\prime}$ is a fixed point, $f\left(X^{\prime}\right)$ is the value of $f(X)$ at point $X^{\prime}, x_{i}$ is the variable in the set of $X, x^{\prime}{ }_{i}$ reperesnts the point $X^{\prime}, f_{x_{i}}\left(X^{\prime}\right)$ is the value of the first order partial derivative of $f(X)$ with respect to the variable $x_{i}$ at point $X^{\prime}$, and $R_{a}$ and $R_{b}$ (positive variables) are remainder terms. The purpose of defining the remainder terms $\left(R_{a}\right.$ and $R_{b}$ ) in Eqs. 37 and 38 is to convert the absolute term to linear terms. The objective of the MILP model is to minimise the remainder terms of all first order Taylor series expansions ${ }^{23}$. If the remainder term is only represented with one variable (e.g. $R=y-\left\{f\left(X^{\prime}\right)+\sum_{i \in I}\left[\left(x_{i}-x_{i}^{\prime}\right) \times f_{x_{i}}\left(X^{\prime}\right)\right]\right\}$, which can be negative or positive), the objective of the 
model must be expressed as: Min $\Sigma|R|$. However, in the new MILP model, Eqs. 37 and 38 use two positive variables $\left(R_{a}\right.$ and $\left.R_{b}\right)$. It can be noted that, when $R$ is positive, $R_{a}$ is larger than $R$, and $R_{b}$ is larger than 0 ; otherwise, when $R$ is negative, $R_{a}$ is larger than 0 , and $R_{b}$ is larger than $(-R)$. Thus, minimising $\Sigma\left(R_{a}+R_{b}\right)$ is the same as minimising $\Sigma|R|$, and the linear terms $\Sigma\left(R_{a}+R_{b}\right)$ can be used to replace the absolute term $\Sigma|R|$ in the MILP objective function.

$$
\begin{aligned}
& y=f(X)=f\left(X^{\prime}\right)+\sum_{i \in I}\left[\left(x_{i}-x_{i}^{\prime}\right) \times f_{x_{i}}\left(X^{\prime}\right)\right]+R_{a}+R_{b}, \quad \forall x_{i} \in X \\
& R_{a} \geq y-\left\{f\left(X^{\prime}\right)+\sum_{i \in I}\left[\left(x_{i}-x_{i}^{\prime}\right) \times f_{x_{i}}\left(X^{\prime}\right)\right]\right\}, \forall x_{i} \in X \\
& R_{b} \geq\left\{f\left(X^{\prime}\right)+\sum_{i \in I}\left[\left(x_{i}-x_{i}^{\prime}\right) \times f_{x_{i}}\left(X^{\prime}\right)\right]\right\}-y, \forall x_{i} \in X
\end{aligned}
$$

In the HEN retrofit model, $y$ is a variable but has a nonlinear relationship $(f(X))$ with other variables $(X)$. Eq. 36 uses first order Taylor series expansion (a linear equation) to represent $y$. In Eqs. 37 and 38, the remainder terms of the first order Taylor series expansion are formulated by using two positive variables $\left(R_{a}\right.$ and $\left.R_{b}\right)$. These positive variables will be minimised in the objective function of the MILP model. And then, the algorithm proposed in our previous work ${ }^{23}$ can be executed iteratively to reduce the remainder terms gradually until a feasible solution is found (namely the remainder terms are very small).

To facilitate understanding of the implementation of first order Taylor series expansion, the correlation of tube-side heat transfer coefficient will be illustrated in details. After this, the equations using first order Taylor expansions for the rest nonlinear correlations will be omitted for shortening the paper substantially.

\section{Tube-side calculations for an exchanger}


To predict heat exchanger performances, the heat transfer coefficients and pressure drops of both tube side and shell side are taken into account. Because of the straightforward fluid behaviour in plain tubes, some well-known correlations, such as Colburn correlation, DittusBoelter correlation, and plain tube pressure drop methods, are accurate for tube-side calculations without tube inserts. ${ }^{2}$ For tube-side heat transfer intensification, some published correlations can be found in recent studies. ${ }^{5}$ In addition, as assumed in the Problem Statement, some tube-side geometry details are assumed constant during the retrofit (such as tube inner diameters and the number of tubes), thus tube-side heat transfer coefficient and pressure drop correlate with tube-side flow rate, tube-side stream temperatures, tube insert density, tube passes and exchanger length. Eqs. 39 and 40 present the correlations of tube-side heat transfer coefficient and pressure drop based on the above assumptions.

$$
\begin{aligned}
& D T E U_{e x, j}=f_{D T E U_{e x, j}}\left(T F R_{e x}, C T I_{e x}, C T O_{e x}, D X_{e x}\right), \forall e x \in E X, j \in J \\
& T E P_{e x, j}=f_{T E P_{e x, j}}\left(T F R_{e x}, C T I_{e x}, C T O_{e x}, D X_{e x}, E X L_{e x}\right), \forall e x \in E X, j \in J
\end{aligned}
$$

In Eqs. 39 and 40, it is assumed that cold stream flows in tube side (stated in Problem Statement), $J$ is the set of all tube-side types including multiple tube passes without/with tube inserts (e.g. one tube pass without inserts, one tube pass with inserts, two tube passes without inserts, two tube passes with inserts, etc.), $D T E U_{e x, j}$ is the reciprocal of tube-side heat transfer coefficient for exchanger $e x$ with the $j^{\text {th }}$ tube-side type, $T E P_{e x, j}$ is the tube-side pressure drop of exchanger $e x$ with the $j^{\text {th }}$ tube-side type, $T F R_{e x}$ is tube-side flow rate, $D X_{e x}$ is tube-insert density, and $E X L_{e x}$ is exchanger length. To linearise the nonlinear terms in Eq. 39, the first order Taylor series expansion is proposed (Eqs. 41-43). In Eq. 41, the derivatives in Taylor series expansion are parameters and evaluated based on the initial values of variables (TFR' $C T I_{e x}, C T O{ }^{\prime}$ and $\left.D X^{\prime}{ }_{e x}\right)$ 


$$
\begin{aligned}
D T E U_{e x, j}= & f_{\text {DTEU }_{e x, j}\left(T F R_{e x}^{\prime}, C T I_{e x}^{\prime}, C T O_{e x}^{\prime}, D X_{e x}^{\prime}\right)} \\
& +\frac{\partial\left[f_{D T E U_{e x, j}}\left(T F R_{e x}^{\prime}, C T I_{e x}^{\prime}, C T O_{e x}^{\prime}, D X_{e x}^{\prime}\right)\right]}{\partial\left(T F R_{e x}\right)} \times\left(T F R_{e x}-T F R_{e x}^{\prime}\right) \\
& +\frac{\partial\left[f_{D T E U_{e x, j}}\left(T F R_{e x}^{\prime}, C T I_{e x}^{\prime}, C T O_{e x}^{\prime}, D X_{e x}^{\prime}\right)\right]}{\partial\left(C T I_{e x}\right)} \times\left(C T I_{e x}-C T I_{e x}^{\prime}\right) \\
& +\frac{\partial\left[f_{D T E U_{e x, j}}\left(T F R_{e x}^{\prime}, C T I_{e x}^{\prime}, C T O_{e x}^{\prime}, D X_{e x}^{\prime}\right)\right]}{\partial\left(C T O_{e x}\right)} \times\left(C T O_{e x}-C T O_{e x}^{\prime}\right) \\
& +\frac{\partial\left[f_{D T E U_{e x, j}}\left(T F R_{e x}^{\prime}, C T I_{e x}^{\prime}, C T O_{e x}^{\prime}, D X_{e x}^{\prime}\right)\right]}{\partial\left(D X_{e x}\right)} \times\left(D X_{e x}-D X_{e x}^{\prime}\right), \quad j \in J \\
& +R a_{D T E U_{e x, j}}+R b_{D T E U_{e x, j}} \\
R a_{D T E U_{e x, j}} \geq & D T E U_{e x, j}-f_{D T E U_{e x, j}}\left(T F R_{e x}^{\prime}, C T I_{e x}^{\prime}, C T O_{e x}^{\prime}, D X_{e x}^{\prime}\right), \quad \forall e x \in E X, j \in J \\
R b_{D T E U_{e x, j}} \geq & f_{D T E U_{e x, j}}\left(T F R_{e x}^{\prime}, C T I_{e x}^{\prime}, C T O_{e x}^{\prime}, D X_{e x}^{\prime}\right)-D T E U_{e x, j} \quad \forall e x \in E X, j \in J
\end{aligned}
$$

The functions for tube-side heat transfer coefficient $\left(f_{\text {DTEUex,j }}()\right)$ can be derived from the well-known correlations in the published papers ${ }^{2,5}$, or defined based on the regression of practical process data ${ }^{39}$. For example, the function of tube-side heat transfer coefficient (Eq. 2) for one tube pass $\left(n_{p}=1\right)$ without tube inserts presented in the motivating example can be expressed as follows:

$$
D T E U_{e x, j}=A_{D T E U_{e x, j}} \times T F R_{e x}^{-0.4} \times e^{-0.007 \times\left(\frac{C T I_{e x}+C T O_{e x}}{2}\right)}
$$

where $A_{D T E U_{e x, j}}$ is the parameter of calculating tube-side heat transfer coefficient of exchanger ex with the $j^{\text {th }}$ tube-side type.

According to Eqs. 41-43, Eq. 44 can be linearised in Eqs. 45-47, where the derivatives in Taylor series expansion are calculated analytically before the MILP problem is solved; $T F{ }_{e x}, C T I_{e x}^{\prime}$ and $C T O{ }_{e x}^{\prime}$ are parameters, and their values will be updated after the MILP problem is solved ${ }^{23}$; two positive variables $\left(R a_{D T E U_{e x, j}}\right.$ and $\left.R b_{D T E U_{e x, j}}\right)$ are remainder term, and to be minimised in the objective function. 


$$
\begin{aligned}
D T E U_{e x, j} & =A_{D T E U_{e x, j}} \times\left(T F R_{e x}^{\prime}\right)^{-0.4} \times e^{-0.007 \times\left(\frac{C T I_{e x}^{\prime}+C T O_{e x}^{\prime}}{2}\right)} \\
& +A_{D T E U_{e x, j}} \times(-0.4) \times\left(T F R_{e x}^{\prime}\right)^{-1.4} \times e^{-0.007 \times\left(\frac{C T I_{e x}^{\prime}+C T O_{e x}^{\prime}}{2}\right)} \times\left(T F R_{e x}-T F R_{e x}^{\prime}\right) \\
& +A_{D T E U_{e x, j}} \times\left(T F R_{e x}^{\prime}\right)^{-0.4} \times e^{-0.007 \times\left(\frac{C T I_{e x}^{\prime}+C T O_{e x}^{\prime}}{2}\right)} \times\left(-\frac{0.007}{2}\right) \times\left(C T I_{e x}-C T I_{e x}^{\prime}\right) \\
& +A_{D T E U_{e x, j}} \times\left(T F R_{e x}^{\prime}\right)^{-0.4} \times e^{-0.007 \times\left(\frac{C T I_{e x}^{\prime}+C T O_{e x}^{\prime}}{2}\right)} \times\left(-\frac{0.007}{2}\right) \times\left(C T O_{e x}-C T O_{e x}^{\prime}\right) \\
& +R a_{D T E U_{e x, j}}+R b_{D T E U_{e x, j}} \\
\forall e x \in E X, & j \in J \quad \forall e x \in E X, j \in J \\
R a_{D T E U_{e x, j}} \geq & D T E U_{e x, j}-A_{D T E U_{e x, j}} \times\left(T F R_{e x}^{\prime}\right)^{-0.4} \times e^{-0.007 \times\left(\frac{C T I_{e x}^{\prime}+C T O_{e x}^{\prime}}{2}\right)}, \quad \forall e x \in E X, j \in J \\
R b_{D T E U_{e x, j}} \geq & A_{D T E U_{e x, j}} \times\left(T F R_{e x}^{\prime}\right)^{-0.4} \times e^{-0.007 \times\left(\frac{C T I_{e x}^{\prime}+C T O_{e x}^{\prime}}{2}\right)}-D T E U_{e x, j}, \forall e x
\end{aligned}
$$

Based on Eqs. 45-47, the correlations of tube-side heat transfer coefficients and pressure drops can be linearised in the same way.

As shown in Eqs. 39 and 40, tube-side heat transfer coefficient and pressure drop are calculated based on different tube-side types. To select suitable tube-side type to each exchanger, a series of binary variables $T E X_{e x, j}$ are defined:

$T E X_{e x, j}= \begin{cases}1 & \text { if } j \text { th tube }- \text { side type is implemented in exchanger ex } \\ 0 & \text { otherwise }\end{cases}$

Only one tube-side type can be assigned to an exchanger, as presented in Eq. 48.

$$
\sum_{j \in J} T E X_{e x, j}=1, \quad \forall e x \in E X
$$


Eqs. 49-52 restrict the tube-side heat transfer coefficient $\left(D T U_{e x}\right)$ and pressure drop $\left(T P_{e x}\right)$ of exchanger ex when its tube-side type is selected, where $D T U_{e x}$ is the reciprocal of tubeside heat transfer coefficient of exchanger $e x, T P_{e x}$ is tube-side pressure drop of exchanger $e x$, and $M$ is a sufficiently large positive number.

$$
\begin{aligned}
& D T U_{e x} \geq D T E U_{e x, j}-M \times\left(1-T E X_{e x, j}\right), \quad \forall e x \in E X, j \in J \\
& D T U_{e x} \leq D T E U_{e x, j}+M \times\left(1-T E X_{e x, j}\right), \quad \forall e x \in E X, j \in J \\
& T P_{e x} \geq E T E P_{e x, j}-M \times\left(1-T E X_{e x, j}\right), \quad \forall e x \in E X, j \in J \\
& T P_{e x} \leq E T E P_{e x, j}+M \times\left(1-T E X_{e x, j}\right), \quad \forall e x \in E X, j \in J
\end{aligned}
$$

\section{Shell-side calculations for an exchanger}

On the shell side, segmental baffles serve the function of directing the flow of shell-side fluid across the tube bundle, thereby enhancing the rate of heat transfer. Compared with the tube-side calculation, the shell-side calculation presents the greatest difficulty due to the complexity of the flow on shell side. Only a few methods are available in the public reports ${ }^{2}$. Additionally, based on the assumptions in the Problem Statement, some shell-side geometry details are constant during the retrofit (such as tube outer diameter, tube bundle, tube pitch, tube layout angle, shell diameter and baffle cut). Thus shell-side heat transfer coefficient and pressure drop correlate with shell-side flow rate, shell-side stream average temperature, baffle spacing, and exchanger length. Eqs. 53 and 54 present the correlations of shell-side heat transfer coefficient and pressure drop based on the above assumptions.

$$
\begin{aligned}
& D S U_{e x}=f_{D S U_{e x}}\left(S F R_{e x}, H T I_{e x}, H T O_{e x}, B S P_{e x}\right), \forall e x \in E X \\
& S E P_{e x}=f_{S E P_{e x}}\left(S F R_{e x}, H T I_{e x}, H T O_{e x}, B S P_{e x}, E X L_{e x}\right), \forall e x \in E X
\end{aligned}
$$


In Eqs. 53 and 54, it is assumed that hot stream flows on the shell side (Problem Statement), $D S U_{e x}$ is the reciprocal of shell-side heat transfer coefficient in exchanger ex, $S E P_{e x}$ is the shell-side pressure drop of exchanger $e x, S F R_{e x}$ is shell-side flow rate, and $B S P_{e x}$ is baffle spacing. The functions for the shell-side heat transfer coefficient $\left(f_{D S U e x}()\right)$ and pressure drop $\left(f_{\text {SEPex }}()\right)$, commonly expressed as nonlinear equations, can be derived from the well-known correlations in the published papers (such as Bell-Delaware, developed BellDelaware, simplifying Tinker method, and Wills-Johnston method $)^{38}$, or defined based on the regression of practical process data ${ }^{2}$. Similar to the linearisation for tube-side calculations (Eqs. 45-47), the first order Taylor series expansion (Eqs. 36-38) can be utilised to linearise Eqs. 53 and 54.

\section{Overall heat transfer coefficient of an exchanger}

Since tube-side and shell-side heat transfer coefficients have been defined, the overall heat transfer coefficient of an exchanger can be formulated as:

$D U_{e x}=\frac{O D_{e x}}{I D_{e x}} \times D T U_{e x}+D S U_{e x}+\frac{O D_{e x} \times \ln \left(O D_{e x} / I D_{e x}\right)}{2 k_{e x}}+\frac{O D_{e x}}{I D_{e x}} \times T F F_{e x}+S F F_{e x}, \forall e x \in E X$

In Eq. 55, $D U_{e x}$ is the reciprocal of overall heat transfer coefficient in exchanger $e x, I D_{e x}$ and $O D_{e x}$ are tube inner and outer diameters in exchanger $e x, k_{e x}$ is tube wall conductivity in exchanger $e x, T F F_{e x}$ and $S F F_{e x}$ are tube-side and shell-side fouling factors.

As $D U_{e x}$ is the reciprocal of overall heat transfer coefficient $\left(U_{e x}\right)$ in exchanger $e x$, the relationship between $D U_{e x}$ and $U_{e x}$ are given in Eq. 56, and can be linearised by using first order Taylor series expansion (Eqs. 36-38). 
$U_{e x}=\frac{1}{D U_{e x}}, \forall e x \in E X$

\section{Number of shell passes for an exchanger}

The number of shell passes is one of important issues addressed in this paper, which directly affects $\mathrm{F}_{\mathrm{T}}$, total heat transfer area and pressure drop in an exchanger. To determine the number of shell passes in an exchanger, a series of binary variables $S P_{e x, n}$ are defined:

$S P_{e x, n}= \begin{cases}1 & \text { if } n \text { shell passes are used in exchanger ex } \\ 0 & \text { otherwise }\end{cases}$

Eq. 57 restricts that only one type of shell pass can be assigned to an exchanger, where $N$ is the set of all shell-pass types (e.g. one shell pass, two shell passes, etc.).

$\sum_{n \in N} S P_{e x, n}=1, \quad \forall e x \in E X$

Then, the number of shell passes in each exchanger $\left(N S P_{e x}\right)$ can be identified by the following equation, where parameter $N S_{n}$ presents the number associated with shell passes $\left(N S_{n}=1\right.$, if $\operatorname{ord}(n)=1$ for one shell pass; $N S_{n}=2$, if $\operatorname{ord}(n)=2$ for two shell passes; and so on).

$N S P_{e x}=\sum_{n \in N}\left(S P_{e x, n} \times N S_{n}\right), \quad \forall e x \in E X$

Heat transfer area of an exchanger 
Eqs. 59 and 60 describe the calculation of exchanger area, where $E X A_{e x}$ is the heat transfer area of exchanger $e x$, and parameter $A E X A_{e x}$ is the heat transfer area per exchanger length in exchanger $e x$, which can be determined based on the constant tube outer diameter $\left(O D_{e x}\right)$ and tube number $\left(N T_{e x}\right)$ in the existing exchangers ${ }^{2}$.

$$
\begin{aligned}
& A E X A_{e x}=N T_{e x} \times \pi \times O D_{e x}, \quad \forall e x \in E X \\
& E X A_{e x}=A E X A_{e x} \times E X L_{e x}, \quad \forall e x \in E X
\end{aligned}
$$

To consider multiple shell passes, the total heat transfer area with multiple shell passes $\left(N E X A_{e x}\right)$ is presented in Eqs. 61 and 62.

$$
\begin{aligned}
& N E X A_{e x} \geq E X A_{e x} \times N S_{n}-M \times\left(1-S P_{e x, n}\right), \quad \forall e x \in E X, n \in N \\
& N E X A_{e x} \leq E X A_{e x} \times N S_{n}+M \times\left(1-S P_{e x, n}\right), \quad \forall e x \in E X, n \in N
\end{aligned}
$$

\section{Energy balance in an exchanger}

In a heat exchanger, the heat duties of cold stream and hot stream must be same due to the restriction of energy balance. Eq. 63 shows the ideal energy balance between the cold stream and hot stream, where the equation variables leading to a nonlinear formulation $\left(S F R_{e x} \times\right.$ $H T I_{e x}, S F R_{e x} \times H T O_{e x}, T F R_{e x} \times C T I_{e x}, T F R_{e x} \times C T O_{e x}$, ) that can be linearised by using first order Taylor series expansion (Eqs. 36-38).

$$
C C P_{e x}^{\prime} \times T F R_{e x} \times\left(C T O_{e x}-C T I_{e x}\right)=H C P_{e x}^{\prime} \times S F R_{e x} \times\left(H T I_{e x}-H T O_{e x}\right), \quad \forall e x \in E X
$$

\section{Heat transfer in an exchanger}


Eq. 64 shows the constraint of heat transfer in an exchanger, namely exchanger heat duty equals to the heat duty from its hot stream. First order Taylor series expansion (Eqs. 36-38) also used to linearise nonlinear terms: $S F R_{e x} \times H T I_{e x}, S F R_{e x} \times H T O_{e x}, U_{e x} \times N E X A_{e x}$.

$$
H C P_{e x}^{\prime} \times S F R_{e x} \times\left(H T I_{e x}-H T O_{e x}\right)=U_{e x} \times N E X A_{e x} \times L M T D_{e x}^{\prime} \times F T_{e x}^{\prime}, \quad \forall e x \in E X
$$

\section{Minimum temperature difference in an exchanger}

Eqs. 65 and 66 restrict the minimum approach temperature in each exchanger with/without heat transfer intensification, where $E N T U_{e x}$ is a binary variable, it equals to 1 if exchanger ex is intensified; otherwise, it is $0 . \Delta T_{\min }$ and $\Delta E T_{\min }$ are the minimum approach temperatures of an exchanger with and without intensification, respectively.

$$
\begin{array}{ll}
H T T_{e X} \geq C T O_{e X}+\Delta T_{\min } \times\left(1-E N T U_{e X}\right)+\Delta E T_{\min } \times E N T U_{e X}, & \forall e x \in E X \\
H T O_{e X} \geq C T I_{e X}+\Delta T_{\min } \times\left(1-E N T U_{e X}\right)+\Delta E T_{\min } \times E N T U_{e X}, & \forall e x \in E X
\end{array}
$$

\section{Stream bypassing for an exchanger}

Mixing of bypass stream and exchanger stream must be considered in this study. As shown in Figure 5, the heat duties of the bypass stream and exchanger stream before and after mixing must be identical due to the restriction of the energy balance. Eqs. 67 and 68 shows the energy balance based on the above restriction, where $S B C P{ }_{s, e x}^{\prime}$ is the initial CP of bypass stream $s$ of exchanger ex, $S C P_{s, e x}^{\prime}$ is the initial CP of stream $s$ in exchanger $e x, B F P_{s, e x}$ is the flowrate of bypass stream $s$ of exchanger ex, $S T I_{s, e x}$ and $S T O_{s, e x}$ are the network inlet and outlet temperatures of exchanger ex in stream $s, H S_{e x}$ and $C S_{e x}$ are the sets of all hot streams and cold streams flowing through exchanger ex. The nonlinear terms $\left(B F R_{s, e x} \times S T I_{s, e x}\right.$, 
$B F R_{s, e x} \times S T O_{s, e x}, S F R_{s, e x} \times S T O_{s, e x}$, and $\left.T F R_{s, e x} \times S T O_{s, e x}\right)$ are linearised based on the first order Taylor series expansions (Eqs. 36-38).

$S B C P_{s, e x}^{\prime} \times B F R_{s, e x} \times\left(S T I_{s, e x}-S T O_{s, e x}\right)=S C P_{s, e x}^{\prime} \times S F R_{e x} \times\left(S T O_{s, e x}-H T O_{e x}\right), \forall S \in H S_{e x} \quad e x \in E X$

$S B C P_{s, e x}^{\prime} \times B F R_{s, e x} \times\left(S T I_{s, e x}-S T O_{s, e x}\right)=S C P_{s, e x}^{\prime} \times T F R_{e x} \times\left(S T O_{s, e x}-C T O_{e x}\right), \quad \forall S \in C S_{e x} \quad$ ex $\in E X$

\section{Parallel exchangers}

Figure 6 shows the variables used for describing parallel exchangers in this study. For parallel exchangers, two constraints must be considered, including the stream mixing after parallel exchangers, and identical pressure drops in parallel exchangers.

Eq. 69 restricts that the heat duties of the parallel exchangers must be identical during stream mixing. EXFR ${ }_{s, e x}$ is the flowrate of parallel exchanger ex in stream $s$, and $P S T O_{s, e x}$ is the outlet temperature of parallel exchanger ex in stream s. PEX is the set of all parallel exchangers. The nonlinear terms $\left(E X F R_{s, e x} \times P S T O_{s, e x}, E X F R_{s, e x} \times S T O_{s, e x}, E X F R_{s, e x} \times\right.$ $\left.P S T O_{s, e x}, E X F R_{s, e x} \times S T O_{s, e x},\right)$ are also linearised by the first order Taylor series expansions (Eqs. 36-38).

$$
\begin{aligned}
& S C P_{s, e x}^{\prime} \times E X F R_{s, e x} \times\left(P S T O_{s, e x}-S T O_{s, e x}\right)=S C P_{s, e x^{\prime}}^{\prime} \times E X F R_{s, e x^{\prime}} \times\left(S T O_{s, e x^{\prime}}-P S T O_{s, e x^{\prime}}\right), \\
& \forall S \in S \quad e x, e x^{\prime} \in P E X
\end{aligned}
$$


Moreover, the pressure drops of the parallel exchangers in the same stream must be same, as shown in Eqs. 70 and 71, where $P E X_{C S}$ and $P E X_{H S}$ are the sets of all parallel exchangers in the same cold stream and hot stream, respectively.

$$
\begin{aligned}
& T P_{e X}=T P_{e x^{\prime}}, \forall e x, e x^{\prime} \in P E X_{C S} \\
& S E P_{e x}=S E P_{e x^{\prime}}, \forall e x, e x^{\prime} \in P E X_{H S}
\end{aligned}
$$

\section{Process streams}

Supply temperatures $\left(H S T I_{h s}\right.$ and $C S T I_{c s}$ in Figure 4) and target temperatures $\left(H S T O_{h s}\right.$ and $C S T O_{c s}$ in Figure 4) of process streams are constant during the retrofit. As shown in Figure 4, the stream temperatures are related to the relevant exchanger temperatures. For a single exchanger, its outlet stream temperature $\left(S T O_{s, e x}\right)$ is equal to the inlet stream temperature of the next exchanger $\left(S T I_{s, e x}\right)$.

$$
S T O_{s, e x}=S T I_{s, e x^{\prime}}, \forall e x, e x^{\prime} \in E X_{S} \quad \operatorname{ord}(e x)+1=\operatorname{ord}\left(e x^{\prime}\right) \quad S \in S
$$

For parallel exchangers, their outlet stream temperatures $\left(P S T O_{s, e x}\right)$ are equal to the inlet stream temperature of the next exchanger $\left(S T I_{s, e x}{ }^{\prime}\right)$.

$$
\text { PSTO }_{s, e x}=S T I_{s, e x^{\prime}}, \forall e x, e x^{\prime} \in E X_{S} \quad \text { ex } \in \text { PEX } \quad \operatorname{ord}(e x)+1=\operatorname{ord}\left(e x^{\prime}\right) \quad s \in S
$$

In addition, Eqs. 74 and 75 present the calculation of the total pressure drop of a stream $\left(T O P_{s}\right)$, where $E X S_{s}$ is the set of all single exchangers in stream $s, P G E X_{s, g}$ is the set of all exchangers in the parallel group $g$ in stream $s, n_{g}$ is the total number of exchangers in the parallel group $g$, and $G_{s}$ is the set of all parallel exchanger groups in stream $s$. 


$$
\begin{aligned}
& T O P_{S}=\sum_{e X \in E X S_{s}} T P_{e X}+\sum_{g \in G_{s}}\left(\frac{\sum_{e x^{\prime} \in P G E X_{s, g}} T P_{e X^{\prime}}}{n_{g}}\right), \forall S \in C S \\
& T O P_{S}=\sum_{e x \in E X S_{s}} S E P_{e X}+\sum_{g \in G_{s}}\left(\frac{\sum_{e X^{\prime} \in P G E X_{s, g}} S E P_{e X^{\prime}}}{n_{g}}\right), \forall S \in H S
\end{aligned}
$$

Thus, the total flowrate of a stream $\left(T O F R_{S}\right)$ can be described as the sum of exchanger flowrate and bypass stream flowrate for a single exchanger or parallel exchangers, as shown in Eqs. 76-79.

$$
\begin{aligned}
& T O F R_{S}=B F R_{s, e x}+T F R_{e x}, \forall e x \in E X S_{s} \quad s \in C S \\
& T O F R_{S}=\sum_{g \in G_{S}}\left(\sum_{e x \in P G E X_{s, g}}\left(\text { BFR }_{S, e X}+\operatorname{TFR}_{e X}\right)\right), \forall S \in C S \\
& \text { TOFR }_{S}=B F R_{s, e x}+S F R_{e X}, \forall e x \in E X S_{s} \quad s \in H S \\
& T O F R_{S}=\sum_{g \in G_{s}}\left(\sum_{e X \in P G E X_{S, g}}\left(B F R_{S, e X}+S F R_{e X}\right)\right), \forall s \in H S
\end{aligned}
$$

\section{Retrofit costs}

The HEN retrofit strategies addressed in this study include increasing/reducing exchanger length (namely adding new exchanger as mentioned in Problem Statement), exchanger stream bypassing, changing tube passes and shell passes, implementing tube inserts, changing baffles spacing, and adding new exchangers. Following binary variables are used to describe the above retrofit strategies: 


$$
\begin{aligned}
& I N E X L_{e X}= \begin{cases}1 & \text { if the length of exchanger } e_{X} \text { increases } \\
0 & \text { otherwise }\end{cases} \\
& R E X L_{e x}= \begin{cases}1 & \text { if the length of exchanger } e x \text { decreases } \\
0 & \text { otherwise }\end{cases} \\
& B P_{s, e x}= \begin{cases}1 & \text { if exchanger } e x \text { has bypass stream in stream } S \\
0 & \text { otherwise }\end{cases} \\
& T U P A_{e X}=\left\{\begin{array}{l}
1 \quad \text { if exchanger } e x \text { has tube }- \text { pass change } \\
0 \quad \text { otherwise }
\end{array}\right. \\
& E_{N T U}= \begin{cases}1 & \text { if exchanger } e x \text { has tube inserts } \\
0 & \text { otherwise }\end{cases} \\
& B S P C_{e X}= \begin{cases}1 & \text { if exchanger } e x \text { has baffle }- \text { spacing change } \\
0 & \text { otherwise }\end{cases} \\
& S P_{e X, n}= \begin{cases}1 & \text { if exchanger } e_{X} \text { has } n \text { shell passes } \\
0 & \text { otherwise }\end{cases}
\end{aligned}
$$

Eqs. 80-88 describe the scenario of increasing and reducing exchanger length, where no more than one activity can be executed simultaneously in one exchanger (Eq. 80), and the change of exchanger length and the relevant costs are shown in Eqs. 81 - 83, and Eqs. 84-89, respectively. $M$ is a sufficiently large positive number. $O R E X L_{e x}$ is the original exchanger length. FCOSTREXL $L_{e x}$ and PCOSTREXL $L_{e x}$ are the fixed cost and variable cost of reducing exchanger length, and FCOSTINEXL $L_{e x}$ and PCOSTINEXL $_{e x}$ are the fixed cost and variable cost of increasing exchanger length.

$$
\begin{aligned}
& \operatorname{REXL}_{e X}+\operatorname{INEXL}_{e X} \leq 1, \forall e X \in E X \\
& E_{X X L_{e X}} \geq \operatorname{OREXL}_{e X} \times I N E X L_{e X}+\operatorname{OREXL}_{e X} \times\left(1-R E X L_{e X}-I N E X L_{e X}\right), \forall e X \in E X \\
& E X L_{e X} \leq \text { OREXL }_{e X} \times R E X L_{e X}+M \times I N E X L_{e X}+\text { OREXL }_{e X} \times\left(1-\operatorname{REXL}_{e X}-I N E X L_{e X}\right)
\end{aligned}
$$




$$
\begin{aligned}
& \operatorname{COSTREXL}_{e X} \geq \text { FCOSTREXL }_{e X}+\operatorname{PCOSTREXL}_{e X} \times E X A_{e X}-M \times\left(1-\operatorname{REXL}_{e X}\right), \forall e X \in E X \\
& \operatorname{COSTREXL}_{e X} \leq \text { FCOSTREXL }_{e X}+\operatorname{PCOSTREXL}_{e X} \times E X A_{e X}+M \times\left(1-\operatorname{REXL}_{e X}\right), \forall e X \in E X \\
& \operatorname{COSTREXL}_{e X} \leq M \times \operatorname{REXL}_{e X}, \forall e X \in E X \\
& \operatorname{COSTINEXL~}_{e X} \geq \text { FCOSTINEXL }_{e X}+\text { PCOSTINEXL }_{e x} \times \text { EXA }_{e X}-M \times\left(1-\operatorname{INEXL}_{e X}\right), \forall e x \in E X \\
& \operatorname{COSTINEXL}_{e X} \leq \text { FCOSTINEXL }_{e X}+\text { PCOSTINEXL }_{e X} \times \text { EXA }_{e X}+M \times\left(1-\operatorname{INEXL}_{e X}\right), \forall e x \in E X \\
& \operatorname{COSTINEXL~}_{e X} \leq M \times \operatorname{INEXL}_{e X}, \forall e x \in E X
\end{aligned}
$$

When a bypass stream is implemented, its flowrate $\left(B F R_{s, e x}\right)$ is larger than 0 , as shown in Eq. 89. The cost of stream bypassing $\left(\operatorname{COSTBP}_{s, e x}\right)$ is formulated in Eq. 90.

$$
\begin{aligned}
& B F R_{s, e x} \geq \frac{B P_{s, e x}}{M}, \forall e x \in E X \quad s \in S \\
& \operatorname{COSTBP}_{s, e x} \geq F \operatorname{FOSTBP} P_{s, e x} \times B P_{s, e x}, \forall e x \in E X \quad s \in S
\end{aligned}
$$

Eq.91 restricts that if the tube-side type of an exchanger $\left(T E X_{e x, j}\right)$ is different from its original type $\left(O R T E X_{e x, j}\right)$, tube-pass change occurs in this exchanger. The cost of tube-pass change $\left(\operatorname{COSTTUPA_{ex}}\right)$ is presented in Eq. 92.

$$
\begin{aligned}
& T U P A_{e X}=\text { ORTEX }_{e X, j}-\sum_{j^{\prime} \in O R J_{e x}} T E X_{e X, j^{\prime}}, \forall e x \in E X \\
& \operatorname{COSTTUPA}_{e X} \geq \text { FCOSTTUPA }_{e X} \times \text { TUPA }_{e X}, \forall e x \in E X
\end{aligned}
$$

In this work, some tube-side types are intensified with tube inserts. The relationship of heat transfer intensification $\left(E N T U_{e x}\right)$ and the relevant tube-side type $\left(T E X_{e x, j}\right)$ is shown in Eq. 93, where ENJ is the set of all tube-side types with tube inserts. 


$$
E N T U_{e X}=\sum_{j \in E N J} T E X_{e X, j}, \forall e X \in E X
$$

Thus, the cost of implementing tube inserts $\left(\right.$ COSTENTU $\left._{e x}\right)$ can be expressed as:

$$
\begin{aligned}
& \operatorname{COSTENTU~}_{e X} \geq \text { FCOSTENTU }_{e X}+\text { PCOSTENTU }_{e X} \times \text { EXA }_{\text {eX }}-M \times\left(1-\text { ENTU }_{e X}\right), \forall e x \in E X \\
& \operatorname{COSTENTU~}_{e X} \leq \text { FCOSTENTU }_{e X}+\text { PCOSTENTU }_{e X} \times \text { EXA }_{e X}+M \times\left(1-\text { ENTU }_{e X}\right), \forall e X \in E X \\
& \operatorname{COSTENTU~}_{e X} \leq M \times \text { ENTU }_{e X}, \forall e X \in E X
\end{aligned}
$$

Eqs. 97-99 present that the cost of baffle spacing change (COSTBSPC $C_{e x}$ ) occurs when the baffle spacing of an exchanger $\left(B S P_{e x}\right)$ is different from its original value $\left(O R B S P_{e x}\right)$.

$$
\begin{aligned}
& B S P_{e X} \geq \text { ORBSP }_{e X}-M \times B S P C_{e X}, \forall e x \in E X \\
& B S P_{e x} \leq \mathrm{ORBSP}_{e X}+M \times B S P C_{e X}, \forall e x \in E X \\
& \operatorname{COSTBSPC}_{e x}=\text { FCOSTBSPC }_{e x} \times B S P C_{e x}, \forall e x \in E X
\end{aligned}
$$

Eq. 100 restricts so that only one type of shell pass can be used in one exchanger. Eqs. 101-103 present the cost of new exchanger $\left(\operatorname{COSTEX}_{e x, j}\right)$ with the $j^{\text {th }}$ tube type. Thus, if the number of shell passes increases, new exchangers are required. The cost of adding a new exchanger $\left(\operatorname{COSTNEX}_{e x}\right)$ is described in Eq. 104, where FCOSTEX $\mathrm{F}_{e x, j}$ and PCOSTEX $\mathrm{PCx}_{\mathrm{i}}$ are the fixed and variable cost for exchanger $e x$ with the $j^{\text {th }}$ tube type, and NEX is the set of all new exchangers.

$$
\sum_{n \in N} S P_{e X, n}=1, \forall e x \in E X
$$




$$
\begin{aligned}
& \operatorname{COSTEX}_{e x, j} \leq \text { FCOSTEX }_{e x, j}+\operatorname{PCOSTEX}_{e X} \times \text { EXA }_{e X}+M \times\left(1-\text { TEX }_{e x, j}\right), \forall e X \in E X \quad j \in J \\
& \operatorname{COSTEX}_{e X, j} \geq \text { FCOSTEX }_{e X, j}+\operatorname{PCOSTEX}_{e X} \times \text { EXA }_{e X}-M \times\left(1-\text { TEX }_{e X, j}\right), \forall e X \in E X \quad j \in J \\
& \operatorname{COSTEX}_{e x, j} \leq M \times T E X_{e x, j}, \forall e x \in E X \quad j \in J \\
& \operatorname{COSTNEX}_{e X}=\sum_{j \in J} \operatorname{COSTEX}_{e x, j}, \forall e X \in N E X
\end{aligned}
$$

\section{Retrofit profit}

The retrofit profit $(E R P)$ can be described as the cost of energy saving $(O C U-C U)$ minus the total retrofitting cost. In Eq. $105, I F Y$ is the interest factor in the investment years, $O C U$ is the original utility cost in the existing HEN, and $A C F$ is the annual cost factor.

$$
\begin{aligned}
E R P & =\operatorname{IFY} \times\left\{(O C U-C U)-A C F \times\left[\sum_{s \in S} \sum_{e x \in E X_{s}} \operatorname{COSTBP}_{s, e x}\right.\right. \\
& \left.\left.+\sum_{e X \in E X}\left(\operatorname{COSTREXL}_{e X}+\operatorname{COSTINEXL}_{e X}+\operatorname{COSTTUPA}_{e X}+\operatorname{COSTENTU~}_{e X}+\operatorname{COSTBSPC}_{e X}+\operatorname{COSTNEX}_{e X}\right)\right]\right\}
\end{aligned}
$$

\section{Objective function}

The objective of the new MILP-based method is to minimise the aforementioned remainder terms of the first order Taylor series expansions, to find a feasible retrofit solution under the restriction of a certain retrofit profit value $(E E R P)$.

$E R P \geq E E R P$

$\min O b j=\sum($ remainder terms for the first order Taylor series expansions $)$

\section{Iteration Algorithm for Optimising the New HEN Retrofit Model}


Some iteration approaches have been proposed by Pan et al. to solve the HEN retrofit problems in certain situations, such as implementation of heat transfer intensification ${ }^{3}$, network topology modification ${ }^{23}$, and fouling and pressure drop restrictions ${ }^{4,25}$. In this work, the reported iteration approaches are developed to address more complex HEN retrofit scenarios, which include temperature dependence of stream CPs, stream and exchanger geometry dependence of heat transfer coefficients and pressure drops, and LMTD correction factor $\left(\mathrm{F}_{\mathrm{T}}\right)$ associated with multiple tube passes and shell passes. An inner iteration loop (Loop 1) is proposed to solve the MILP model iteratively to find a feasible retrofit solution under a certain retrofit profit $(E E R P)$, thus the decision variables, their bounds, parameters, and constraints of the inner iteration loop (Loop 1) are the same as those used in the MILP model (from Eqs. 23-107). While in an outer iteration (Loop 2), the estimated retrofit profit $(E E R P)$ will increasing gradually, and the inner iteration loop (Loop 1) is executed repeatedly to find the feasible solutions under these increasing values of retrofit profit (EERP). Thus, there are no additional decision variables and constraints considered in Loop 2, where only the value of parameter EERP (estimated retrofit profit) in the MILP model will increase before running each inner iteration loop (Loop 1). Figure 7 presents the procedure for the two loops. The details of each loop are introduced as follows:

\section{Loop 1}

In Loop 1, the proposed MILP problem is solved iteratively to find the feasible solution to achieve a certain retrofit profit.

Step 1: Input the initial values of variables $\left(H T I_{e x}^{\prime}, H T O_{e x}^{\prime}, C T I_{e x}^{\prime}, C T O_{e x}^{\prime}, L M T D_{e x}^{\prime}\right.$, $\left.F T^{\prime}{ }_{e x}, \ldots\right)$ in the retrofit model (MILP) based on the HEN original condition. Set the iteration time $(\mathrm{k})$ for Loop $1: \mathrm{k}=1$.

Step 2: Solve the MILP model in GAMS. 
Step 3: Obtain the results of the MILP problem $\left(\mathrm{Obj}, H T I_{e x}, H T O_{e x}, C T I_{e x}, C T O_{e x}, L M T D_{e x}\right.$, $\left.F T_{e x}, \ldots\right)$.

Step 4: If the objective value $(O b j)$ is less than a specified tolerance (namely a feasible solution is found), Loop 2 can be executed to increase the estimated retrofit profit $($ EERP $)$; otherwise, update the iteration time $(\mathrm{k})$ for Loop 1 as: $\mathrm{k}($ new $)=\mathrm{k}($ old $)+1$.

Step 5: If the iteration time (k) for Loop 1 is larger the maximum iteration time (namely no feasible solution can be found under the restriction of the estimated retrofit profit $(E E R P))$, Loop 1 will stop; otherwise, update the initial values of variables in the MILP problem. For example, $H T I^{\prime}{ }_{e x}($ new $)=\left[H T I^{\prime}{ }_{e x}(\right.$ old $\left.)+H T I_{e x}\right] / 2$, and $H T O^{\prime}{ }_{e x}$ $($ new $)=\left[H T O^{\prime}{ }_{e x}(\right.$ old $\left.)+H T O_{e x}\right] / 2$. Then, execute from Step 2 to Step 5 iteratively.

\section{Loop 2}

For Loop 2, the retrofit profit of the HEN retrofit problem is estimated as a small value at first, and Loop 1 is used to find the feasible solution under this small estimated value, then the estimated retrofit profit will increase gradually in Loop 2 until the solution can achieve the maximum retrofit profit.

Step 1: Estimate a small value of retrofit profit $(E E R P)$, usually EERP $=0$ in the first iteration.

Step 2: Execute Loop 1 based on this EERP.

Step 3: If a feasible solution can be found based on the above EERP in Loop 1, increase the value of EERP gradually, and return to Step 2. Once no feasible solution can be found in Loop 1 when the EERP increases to a larger value, Loop 2 can stop, and the approximate maximum retrofit profit is determined.

The strategy of changing EERP for Step 3 is shown in Eq.108. 


$$
E E R P=\left\{\begin{array}{l}
0, \quad k=1 \\
10^{(k-1)}, \quad 1<k<k^{1} \\
10^{\left(k^{1}-2\right)}+10^{\left(k^{1}-2\right)} \times\left(k-k^{1}\right), \quad k^{1}<k<k^{2} \\
10^{\left(k^{1}-2\right)}+10^{\left(k^{1}-2\right)} \times\left(k^{2}-k^{1}-1\right)+10^{\left(k^{1}-3\right)} \times\left(k-k^{2}\right), \quad k^{2}<k<k^{3} \\
10^{\left(k^{1}-2\right)}+10^{\left(k^{1}-2\right)} \times\left(k^{2}-k^{1}-1\right)+10^{\left(k^{1}-3\right)} \times\left(k^{3}-k^{2}-1\right)+10^{\left(k^{1}-4\right)} \times\left(k-k^{3}\right), \quad k^{3}<k
\end{array}\right.
$$

To explain Eq. 107 more clearly, an illustration of finding MaxERP $=5624$ is given as follow:

- In the first iteration $(k=1): E E R P=0$, which means to find a feasible solution with no retrofit profit.

- For $1<k<k^{1}: k=2, E E R P=10$ (feasible); $k=3, E E R P=100$ (feasible); $k=4, E E R P=$ 1000 (feasible); $k=5, E E R P=10000$ (infeasible), so $k^{1}=5$.

- For $k^{1}<k<k^{2}: k=6, E E R P=2000$ (feasible); $k=7, E E R P=3000$ (feasible); $k=8, E E R P$ $=4000$ (feasible); $k=9, E E R P=5000$ (feasible); $k=10, E E R P=6000$ (infeasible), so $k^{2}=10$.

- For $k^{2}<k<k^{3}: k=11, E E R P=5100$ (feasible); $k=12, E E R P=5200$ (feasible); $k=13$, $E E R P=5300$ (feasible); $k=14, E E R P=5400$ (feasible); $k=15, E E R P=5500$ (feasible); $k=16, E E R P=5600$ (feasible) $k=17, E E R P=5700$ (infeasible), so $k^{3}=17$.

- For $k^{3}: k=18, E E R P=5610$ (feasible). Since, [EERP $(k=18)-$ EERP $\left.(k=16)\right] /$ EERP $(k=18)=0.00178$, EERP $(k=18)=5610$ can be regarded as the approximation of the $\operatorname{Max} \operatorname{ERP}(5624)$.

\section{Case Study}

Besides the motivating example, one industrial scale example are used to demonstrate the new model and the efficiency of the proposed optimisation algorithm. Practical operating conditions of HENs are taken into account, including the temperature dependence of stream 
CPs, the stream and exchanger geometry dependence of heat transfer coefficients and pressure drops, and LMTD correction factor $\left(\mathrm{F}_{\mathrm{T}}\right)$ associated with multiple tube passes and shell passes. Thus, the same calculations applied in the motivating example are used in these two examples, namely the stream CP in an exchanger is assumed as a linear relationship with the stream average temperature, and the formulations of heat transfer coefficients and pressure drops in an exchanger are regressed based on the detailed exchanger models proposed by Wang et al. ${ }^{2}$ and Pan et al. ${ }^{5}$.

- The stream CP in an exchanger:

$$
C P=A_{C P} \times T_{\text {stream }}^{\text {ave }}-B_{C P}
$$

- The heat transfer coefficient and pressure drop of an exchanger:

$$
\begin{array}{ll}
h_{i}^{-1}=A_{h i} \times F R_{i}^{-0.4} \times e^{-0.007 T_{i}^{\text {ave }}} & \text { without tube inserts } \\
h_{i e}^{-1}=A_{h i e} \times F R_{i}^{-0.6} \times e^{-0.007 T_{i}^{\text {ave }}} \times \rho_{\text {insert }}^{-1.0392} \quad \text { with tube inserts } \\
\Delta P_{i}=A_{p i} \times F R_{i}^{1.7415} \times e^{-0.003 T_{i}^{\text {ave }}} \times L \quad \text { without tube inserts } \\
\Delta P_{i e}=A_{p i e} \times F R_{i}^{1.85} \times e^{-0.003 T_{i}^{T_{\text {vev }}}} \times L \times\left(2072.73-33.82 \rho+\rho^{2}\right) \quad \text { with tube inserts } \\
h_{0}^{-1}=A_{h 0} \times F R_{0}^{-0.35} \times e^{-0.006 T_{0}^{\text {ave }}} \times B S^{1.4444} \\
\Delta P_{0}=A_{p 0} \times F R_{0}^{1.322} \times e^{-0.0045 T_{0}^{\text {Tive }}} \times L \times\left(0.179+0.041 B S-B S^{2}\right)
\end{array}
$$

All optimisation problems are modeled in GAMS 24.3.3, and solved with CPLEX on a computer with an Intel(R) Core(TM) i7-6700 CPU @ 3.40 GHz and 8 GB RAM.

This large example is the HEN in a preheat train for crude oil distillation in a petroleum refinery. As shown in Figure 8, it includes 31 heat exchangers and 14 processing streams (3 cold streams and 11 hot streams). Some studies have addressed this example based on the simplifying operating conditions, especially for constant exchanger geometry, heat transfer coefficients and pressure drops $2,3,26$. However, this does not normally happen in practice. Tables 5 and 6 present the parameters for calculating variable stream CPs, and exchanger 
heat transfer coefficients and pressure drops. It is noted in Table 7 that, retrofitting exchangers are much more expensive for industrial application compared to the motivating example, such as higher variable costs for implementing tube inserts and adding new exchangers, and significant costs of changing tube passes, shell passes and baffle spacing. The exchanger detailed performances and retrofit costs for large-scale example can be found in Tables 10-12. The expected project lifetime is four years based on the assumption of $0 \%$ rate of interest.

Since higher retrofit costs are taken into account in the industrial application, the retrofitted HEN of large-scale example includes following features:

- Ten exchangers are enhanced (namely implementing tube inserts).

- Geometry details are justified in fewer exchangers: no tube-pass change and shellpass change, and eight exchangers for changing baffle spacing.

- Exchangers 20 and 28 are single tube pass due to their inefficient $\mathrm{F}_{\mathrm{T}}$ value before and after the retrofit.

- For parallel exchangers (Exchangers 1 and 3 in Stream C1, and Exchangers 16 and 17 in Stream C2), the exchangers in the same parallel group have the same pressure drop by adjusting their fluid flowrates and exchanger geometry parameters. For instance, the tube side pressure drops of Exchangers 1 and 3 are both $18.2 \mathrm{kPa}$ in the original HEN, and then these pressure drops are reduced to $40.8 \mathrm{kPa}$ in the retrofitted HEN.

- The streams in gas phase usually lead to low pressure drops. It can be seen in Tables 11 and 12 that, some low-pressure drops can be found (Exchangers 7, 10 and 20) in the original and retrofitted networks as the streams in these exchangers are in gas phase.

- As presented in Table 9, the total pressure drop in each stream is lower than $380 \mathrm{kPa}$ after HEN retrofitting, which satisfies the restriction of the maximum pump duty in 
each stream. The pressure drops of some streams (such as $16 \%$ in $\mathrm{C} 1,27.2 \%$ in $\mathrm{C} 2$, $64.9 \%$ in $\mathrm{C} 3,5.2 \%$ in $\mathrm{H} 1,41.3 \%$ in $\mathrm{H} 5,0.6 \%$ in $\mathrm{H} 7$, and $0.9 \%$ in $\mathrm{H} 11$ ) increase due to heat transfer enhancements.

- In the original HEN, the minimum approach temperatures of all exchangers are $19{ }^{\circ} \mathrm{C}$, and Exchanger 18, 20-23 and 28 reach this minimum approach temperature (calculated based on Table 11). By implementing heat transfer intensification techniques in exchangers, very high heat transfer coefficients can be achieved, and the minimum approach temperature can be set to $5{ }^{\circ} \mathrm{C}$ for each intensified exchanger. Thus, the minimum approach temperatures of intensified exchangers (Exchangers 1, $3,10,18,20,22,23,24,26$ and 28$)$ are $5{ }^{\circ} \mathrm{C}$, and the exchangers without intensification remain the original minimum approach temperatures $\left(19{ }^{\circ} \mathrm{C}\right)$ in the retrofitted HEN, which can be obtained from Table 12.

- In the retrofitted solution given by the new approach, substantial heat recovery $(1979 \mathrm{~kW})$ can be achieved through upgrading a few exchangers. This results in $\$ 194334$ of retrofit profit for the four years of the project lifetime.

- In the retrofit solutions obatined from the conventional intensification approaches, exchanger heat transfer coefficients and pressure drops are assumed to be constant if this exchanger does not need to be enhanced. Based on this assumption, only a few intensified exchangers have increased heat transfer coefficients and pressure drops during the retrofit ${ }^{2,3,26}$. However, the inlet and outlet temperatures in most of the exchangers usually change after HEN retrofitting. Thus, in practical problems, the performances of unmodified exchangers may change due to their temperaturedependent characteristics, such as the temperature dependence of stream CPs, and the temperature dependence of heat transfer coefficients and pressure drops. It can be noted in our retrofit solution that, after ten exchangers are enhanced (implementing 
tube inserts), one or more retrofit strategies (changing exchanger area, tube passes, baffle spacing, and bypass stream flowrates) are applied to the related exchangers. This can adjust the performances of all exchangers to satisfy the energy balances and pressure drop restrictions, and increase the HEN heat recovery in the conditions of constant stream supply and target temperatures.

Table 8 also presents the model statistics and computing times of the MILP problems solved in the large-scale example. It includes more binary variables, continuous variables, and constraints compared with the motivating example, thus requires a longer CPU time. However, the new approach can solve this complex industrial scale problem in an acceptable computing time (about 3127 CPUs in total).

\section{Conclusion}

In this paper, the MILP converted model and iteration algorithm are developed to solve large-scale HEN retrofitting problems for industrial application. The new approach features actual HEN scenarios such as temperature dependence of stream CPs, thermal and hydraulic calculations for each exchanger based on geometry details and stream temperatures, adding new exchangers, LMTD correction factor $\left(\mathrm{F}_{\mathrm{T}}\right)$ associated with the change of tube passes and shell passes, and implementation of tube inserts and bypass streams. A set of variable initialised equations and first order Taylor series expansions are proposed to convert the nonlinear terms to linear terms. Thus, HEN retrofitting problems can be formulated as MILP models to reduce the problem computational complexities. In order to find the optimal solutions of HEN retrofitting, an iteration algorithm is then developed. The solution algorithm is composed of two loops, which are executed iteratively until the stop criterion is met. Our approach is applied to one small scale problem (motivating example) and one largescale problem modified from a real-life HEN (case study). It is observed that the proposed 
approach can find optimal retrofit solutions for practical HEN retrofitting problems efficiently. So far, the complex HEN retrofit scenarios addressed in our work have not been reported in the existing literature. It is still difficult to demonstrate the global optimization of MILP-based iteration method. The best way, for validating the MILP-based iteration method, is to compare this method with other existing methods by solving literature case studies under some simplifications and assumptions. This has been reported in our earlier work ${ }^{23}$.

\section{Acknowledgments}

Financial support from 100 Top Talents Program of Sun Yat-Sen University, and FP7-SME2010-1 (262205 Intensified Heat Transfer Technologies for Enhanced Heat Recovery) are gratefully acknowledged.

\section{Notation}

\section{Indices}

$\begin{array}{ll}\text { cs } & \text { cold stream } \\ e x & \text { heat exchanger } \\ g & \text { parallel exchanger } \\ h s & \text { hot stream } \\ s & \text { stream }\end{array}$

Sets

CS $\quad$ set of all cold streams

$C S_{e x} \quad$ set of all cold streams flowing through exchanger ex

ENJ set of all tube-side types with tube inserts

$E X \quad$ set of all exchangers

$E X_{c u} \quad$ set of all exchangers consuming cold utilities

$E X_{h u} \quad$ set of all exchangers consuming hot utilities

$E X S_{s} \quad$ set of all single exchangers in stream $s$

$G_{s} \quad$ set of all parallel exchanger groups in stream $s$

$H S_{e x} \quad$ set of all hot streams flowing through exchanger $e x$

$N \quad$ set of all shell-pass types

NEX set of all new exchangers

PEX set of all parallel exchangers

$P E X_{C S} \quad$ set of all parallel exchangers in the same cold stream

$P E X_{H S} \quad$ set of all parallel exchangers in the same hot stream

$P G E X_{s, g} \quad$ set of all exchangers in the parallel group $g$ in stream $s$

$S \quad$ set of all streams 


\section{Parameters}

\begin{tabular}{|c|c|}
\hline$\Delta T_{\min }$ & minimum approach temperature \\
\hline$A C F$ & annual cost factor \\
\hline$A_{C P}$ & parameter to calculate temperature dependence of $C P$ \\
\hline$A_{D T E U_{e x, j}}$ & $\begin{array}{l}\text { parameter of calculating tube-side heat transfer coefficient of exchanger } e x \\
\text { with the } j^{\text {th }} \text { tube-side type }\end{array}$ \\
\hline$A E X A_{e x}$ & heat transfer area per exchanger length in exchanger $e x$ \\
\hline$A_{h 0}$ & parameter to calculate shell side heat transfer coefficient $\left(h_{0}\right)$ \\
\hline$A_{h i}$ & $\begin{array}{l}\text { parameter to calculate tube side heat transfer coefficient without tube } \\
\text { inserts }\left(h_{i}\right)\end{array}$ \\
\hline$A_{\text {hie }}$ & $\begin{array}{l}\text { parameter to calculate tube side heat transfer coefficient with tube inserts } \\
\left(h_{i e}\right)\end{array}$ \\
\hline$A_{p 0}$ & parameter to calculate shell side pressure drop $\left(\Delta P_{0}\right)$ \\
\hline$A_{p i}$ & parameter to calculate tube side pressure drop without tube inserts $\left(\Delta P_{i}\right)$ \\
\hline$A_{\text {pie }}$ & parameter to calculate tube side pressure drop with tube inserts $\left(\Delta P_{i e}\right)$ \\
\hline$B_{C P}$ & parameter to calculate temperature dependence of $C P$ \\
\hline$C C P_{e x}^{\prime}$ & initial cold stream CP in exchanger $e x$ \\
\hline$C C U$ & yearly cost parameter per cold-utility-duty unit \\
\hline $\mathrm{CHU}$ & yearly cost parameter per hot-utility-duty unit \\
\hline$C S T I_{c s}$ & cold stream supply temperature in a HEN \\
\hline CSTO $_{c s}$ & cold stream target temperature in a HEN \\
\hline CTI ${ }_{e x}$ & initial inlet temperature of cold stream in exchanger $e x$ \\
\hline$C T O^{\prime}$ ex & initial outlet temperature of cold stream in exchanger $e x$ \\
\hline DTEU $_{e x, j}^{\prime}$ & $\begin{array}{l}\text { initial value of the reciprocal of tube-side heat transfer coefficient for } \\
\text { exchanger } e x \text { with the } j^{\text {th }} \text { tube-side type }\end{array}$ \\
\hline$D X_{e x}^{\prime}$ & initial tube-insert density in exchanger $e x$ \\
\hline EERP & estimated retrofit profit for each iteration in Loop 2 \\
\hline$F C O S T B P_{s, e x}$ & fixed cost of stream bypassing in exchanger $e x$ \\
\hline$F C O S T B S P C_{e x}$ & fixed cost of baffle spacing change in exchanger $e x$ \\
\hline FCOSTENTU $U_{e x}$ & fixed cost of implementing tube inserts in exchanger $e x$ \\
\hline$F_{C O S T E X} X_{e x, j}$ & fixed cost of new exchanger with the $j^{\text {th }}$ tube type \\
\hline FCOSTINEXL $_{e x}$ & fixed cost of increasing length in exchanger $e x$ \\
\hline FCOSTREXL $L_{e x}$ & fixed cost of reducing length in exchanger $e x$ \\
\hline FCOSTTUPA $A_{e x}$ & fixed cost of tube-pass change in exchanger $e x$ \\
\hline$F T_{e x}^{\prime}$ & initial FT value of exchanger $e x$ \\
\hline$H C P_{e x}^{\prime}$ & initial hot stream CP in exchanger $e x$ \\
\hline$H S T I_{h s}$ & hot stream supply temperature in a HEN \\
\hline$H S T O_{h s}$ & hot stream target temperature in a HEN \\
\hline$H T I_{e x}^{\prime}$ & initial inlet temperature of hot stream in exchanger $e x$ \\
\hline$H T O_{e x}^{\prime}$ & initial outlet temperature of hot stream in exchanger $e x$ \\
\hline$I D_{e x}$ & tube inner diameter in exchanger $e x$ \\
\hline IFY & interest factor in the investment years \\
\hline$k_{\text {ex }}$ & tube wall conductivity in exchanger $e x$ \\
\hline$L M T D_{e x}$ & initial logarithmic mean temperature difference (LMTD) of exchanger ex \\
\hline$M$ & a sufficiently large positive number \\
\hline$n_{g}$ & total number of exchangers in the parallel group $g$ \\
\hline$N S_{n}$ & number associated with shell passes \\
\hline$N S P_{e x}^{\prime}$ & initial number of shell passes in exchanger $e x$ \\
\hline
\end{tabular}




\begin{tabular}{|c|c|}
\hline$O C T I_{e x}$ & inlet temperature of cold stream in exchanger $e x$ in the original HEN \\
\hline$O C U$ & original utility cost in the existing HEN \\
\hline$O D_{e x}$ & tube outer diameter in exchanger $e x$ \\
\hline $\mathrm{OHTI}_{e x}$ & inlet temperature of hot stream in exchanger $e x$ in the original HEN \\
\hline$O R B S P_{e x}$ & Original baffle spacing in exchanger $e x$ \\
\hline$O R E X L_{e x}$ & original length of exchanger $e x$ \\
\hline ORTEX $X_{e x, j}$ & Original tube type in exchanger $e x$ \\
\hline$P_{e x}^{\prime}$ & factor used to calculate $F T^{\prime}$ in exchanger $e x$ \\
\hline PCOSTENTU $_{e x}$ & variable cost of implementing tube inserts in exchanger $e x$ \\
\hline$P C O S T E X_{e x, j}$ & variable cost of new exchanger with the $j^{\text {th }}$ tube type \\
\hline PCOSTINEXL $L_{e x}$ & variable cost of increasing length in exchanger $e x$ \\
\hline$P_{C O S T R E X L}$ & variable cost of reducing length in exchanger $e x$ \\
\hline$P S C P_{s, e x}^{\prime}$ & initial CP of stream $s$ in parallel exchanger ex \\
\hline$R_{e x}^{\prime}$ & factor used to calculate $F T^{\prime}$ in exchanger $e x$ \\
\hline$S_{e x}^{\prime}$ & factor used to calculate $F T^{\prime}$ in exchanger $e x$ \\
\hline$S B C P_{s, e x}^{\prime}$ & initial CP of bypass stream $s$ in exchanger $e x$ \\
\hline$S C P_{s, e x}^{\prime}$ & initial CP of stream $s$ in exchanger $e x$ \\
\hline$S F F_{e x}$ & shell-side fouling factor in exchanger $e x$ \\
\hline$T F F_{e x}$ & tube-side fouling factor in exchanger $e x$ \\
\hline$T_{F R}^{\prime}{ }_{e x}$ & initial tube-side flow rate in exchanger $e x$ \\
\hline$Y R$ & expected project lifetime \\
\hline$\alpha_{e x}^{\prime}$ & factor used to calculate $F T$ ' in exchanger $e x$ \\
\hline
\end{tabular}

\section{Continuous variables}

$\begin{array}{ll}T_{i}^{a v e} & \text { stream average temperatures in tube side } \\ T_{0}^{a v e} & \text { stream average temperatures in shell side } \\ \Delta P_{0} & \text { shell side pressure drop } \\ \Delta P_{i} & \text { tube side pressure drop without tube inserts } \\ \Delta P_{i e} & \text { tube side pressure drop with tube inserts } \\ B F R_{s, e x} & \text { flow rate of bypass stream } s \text { in exchanger } e x \\ B S & \text { baffle spacing } \\ B S P_{e x} & \text { baffle spacing of exchanger ex } \\ C B P & \text { cost of changing stream bypassing } \\ C B S & \text { cost of changing baffle spacing } \\ C F C P_{e x} & \text { heat-flow capacity (the multiplication between heat capacity and flow-rate) } \\ & \text { of cold stream in exchanger ex } \\ C I L_{e x} & \text { cost of increasing length in exchanger } e x \\ C O S T B P_{s, e x} & \text { cost of stream bypassing in exchanger } e x \text { in stream } s \\ C O S T B S P C_{e x} & \text { cost of baffle spacing change in exchanger } e x \\ C O S T E N T U_{e x} & \text { cost of implementing tube inserts in exchanger } e x \\ C O S T E X_{e x, j} & \text { cost of new exchanger with the } j^{\text {th }} \text { tube type } \\ C O S T I N E X L_{e x} & \text { cost of increasing length in exchanger } e x \\ C O S T R E X L_{e x} & \text { cost of reducing length in exchanger } e x \\ C O S T T U P A_{e x} & \text { cost of tube-pass change in exchanger } e x \\ C P & \text { specific heat capacities } \\ C R L_{e x} & \text { cost of reducing length in exchanger } e x \\ C T E_{e x} & \text { cost of implementing tube inserts in exchanger } e x \\ C T I_{e x} & \text { inlet temperature of cold stream in exchanger } e x \\ & \end{array}$




\begin{tabular}{|c|c|}
\hline$C T O_{e x}$ & outlet temperature of cold stream in exchanger $e x$ \\
\hline CTP & cost of changing tube passes \\
\hline$D S U_{e x}$ & the reciprocal of shell-side heat transfer coefficient in exchanger $e x$ \\
\hline$D T E U_{e x, j}$ & $\begin{array}{l}\text { the reciprocal of tube-side heat transfer coefficient for exchanger } e x \text { with } \\
\text { the } j^{\text {th }} \text { tube-side type }\end{array}$ \\
\hline$D T U_{e x}$ & reciprocal of tube-side heat transfer coefficient of exchanger $e x$ \\
\hline$D U_{e x}$ & the reciprocal of overall heat transfer coefficient in exchanger $e x$ \\
\hline$D X_{e x}$ & tube-insert density in exchanger $e x$ \\
\hline$E R P$ & retrofit profit after tax accumulated over the expected lifetime \\
\hline$E T E P_{e x, j}$ & $\begin{array}{l}\text { estimated value of tube-side pressure drop of exchanger } e x \text { with the } j^{\text {th }} \\
\text { tube-side type }\end{array}$ \\
\hline$E X F R_{s, e x}$ & flowrate of parallel exchanger ex in stream $s$ \\
\hline$E X L_{e x}$ & length of exchanger $e x$ \\
\hline$F C B P$ & fixed cost of changing stream bypassing \\
\hline$F C B S$ & fixed cost of changing baffle spacing \\
\hline$F C I L_{e x}$ & fixed cost for increasing length in exchanger $e x$ \\
\hline$F C R L_{e x}$ & fixed cost for reducing length in exchanger $e x$ \\
\hline$F C T E_{e x}$ & fixed cost for implementing tube inserts in exchanger $e x$ \\
\hline FCTP & fixed cost for changing tube passes \\
\hline$F R_{0}$ & flow rates in shell side \\
\hline$F R_{i}$ & flow rates in tube side \\
\hline$F T_{e x}$ & FT value of exchanger $e x$ \\
\hline$h_{0}$ & shell side heat transfer coefficient \\
\hline$H C P_{e x}$ & hot stream CP in exchanger $e x$ \\
\hline$H F C P_{e x}$ & $\begin{array}{l}\text { heat-flow capacity (the multiplication between heat capacity and flow-rate) } \\
\text { of hot stream in exchanger } e x\end{array}$ \\
\hline$h_{i}$ & tube side heat transfer coefficient without tube inserts \\
\hline$h_{i e}$ & tube side heat transfer coefficient with tube inserts \\
\hline$H T I_{e x}$ & inlet temperature of hot stream in exchanger $e x$ \\
\hline$H T O_{e x}$ & outlet temperature of hot stream in exchanger $e x$ \\
\hline$L$ & exchanger length \\
\hline$L M T D_{e x}$ & logarithmic mean temperature difference (LMTD) of exchanger $e x$ \\
\hline$N B P$ & number of exchangers with changed stream bypassing \\
\hline NBS & number of exchangers with changed baffle spacing \\
\hline$N E X A_{e x}$ & total heat transfer area with multiple shell passes \\
\hline$N S P_{e x}$ & number of shell passes in exchanger $e x$ \\
\hline$N T P$ & number of exchangers with changed tube passes \\
\hline Obj & Objective value \\
\hline$P C I L_{e x}$ & variable cost for increasing length in exchanger $e x$ \\
\hline$P C R L_{e x}$ & variable cost for reducing length in exchanger $e x$ \\
\hline$P C T E_{e x}$ & variable cost for implementing tube inserts in exchanger $e x$ \\
\hline$P_{e x}$ & factor used to calculate FT in exchanger $e x$ \\
\hline PES & profit of reducing energy consumption \\
\hline$P_{S T O}, e x$ & temperature of mixed streams after parallel exchangers in stream $s$ \\
\hline$R a_{D T E U_{e x, j}}$ & remainder term of first order Tylor series expansion of $D T E U_{e x, j}$ \\
\hline$R b_{D T E U_{e x, j}}$ & remainder term of first order Tylor series expansion of $D T E U_{e x, j}$ \\
\hline$R_{e x}$ & factor used to calculate FT in exchanger $e x$ \\
\hline$R P$ & retrofit profit before tax accumulated over the expected lifetime \\
\hline$S E P_{e x}$ & shell-side pressure drop of exchanger $e x$ \\
\hline
\end{tabular}




$\begin{array}{ll}S_{e x} & \text { factor used to calculate FT in exchanger } e x \\ S F R_{e x} & \text { shell-side flow rate in exchanger } e x \\ S T I_{s, e x} & \text { stream temperature in exchanger } e x \text { before mixed with bypass stream } s \\ S T O_{s, e x} & \text { stream temperature in exchanger } e x \text { after mixed with bypass stream } s \\ T E P_{e x, j} & \text { tube-side pressure drop of exchanger } e x \text { with the } j^{\text {th }} \text { tube-side type } \\ T F R_{e x} & \text { tube-side flow rate in exchanger } e x \\ T O F R_{s} & \text { total flowrate of stream } s \\ T O P_{s} & \text { total pressure drop in stream } s \\ T P_{e x} & \text { tube-side pressure drop of exchanger } e x \\ U_{e x} & \text { overall heat transfer coefficient of exchanger } e x \\ \alpha_{e x} & \text { factor used to calculate FT in exchanger } e x \\ \rho & \text { tube-insert density }\end{array}$

\section{Binary variables}

$B P_{s, e x} \quad 1$ if exchanger $e x$ has bypass stream in stream s; otherwise it is 0

$B S P C_{e x} \quad 1$ if exchanger $e x$ has baffle-spacing change; otherwise it is 0

$E N T U_{e x} \quad 1$ if exchanger $e x$ has tube inserts; otherwise it is 0

$I N E X L_{e x} \quad 1$ if the length of exchanger ex increases; otherwise it is 0

$R E X L_{e x} \quad 1$ if the length of exchanger ex decreases; otherwise it is 0

$S P_{e x, n} \quad 1$ if exchanger $e x$ has $n$ shell passes; otherwise it is 0

$T E X_{e x, j} \quad 1$ if $j^{\text {th }}$ tube-side type is implemented in exchanger ex; otherwise it is 0

$T_{U P A_{e x}} \quad 1$ if exchanger $e x$ has tube-pass change; otherwise it is 0

\section{Literature Cited}

1. Sreepathi BK, Rangaiah GP. Review of exchanger network retrofitting methodologies and their applications. Ind Eng Chem Res. 2014;53:11205-11220.

2. Wang Y, Pan M, Bulatov I, Smith R, Kim JK. Application of intensified heat transfer for the retrofit of heat exchanger network. Appl Energy. 2012;89(1):45-59.

3. Pan M, Butalov I, Smith R, Kim JK., Novel MILP-based iterative method for the retrofit of heat exchanger networks with intensified heat transfer. Comput Chem Eng. 2012;42:263-276.

4. Pan M, Butalov I, Smith R. Improving heat recovery in retrofitting heat exchanger networks with heat transfer intensification, pressure drop constraint and fouling mitigation. Appl Energy. 2016;161:611-626.

5. Pan M, Jamaliniya S, Smith R, Bulatov I, Gough M, Higley T, Droegemueller P. New insights to implement heat transfer intensification for shell and tube heat exchangers. Energy. 2013;57:208-221.

6. Asante NDK., Zhu XX. An automated approach for heat exchanger network retrofit featuring minimal topology modifications. Comput Chem Eng. 1996;20:S7-S12.

7. Zhu XX, Asante NDK. Diagnosis and optimization approach for heat exchanger network retrofit. AIChE J. 1999;45(7):1488-1503.

8. Nie XR, Zhu XX. Heat exchanger network retrofit considering pressure drop and heattransfer enhancement. AIChE J. 1999;45(6):1239-1254.

9. Li BH, Chang CT. Retrofitting heat exchanger networks based on simple pinch analysis. Ind Eng Chem Res. 2010;49:3967-3971.

10. Nordman R, Berntsson T. Use of advanced composite curves for assessing cost-effective 
HEN retrofit I: Theory and concepts. Appl Therm Eng. 2009;29:275-281.

11. Gadalla MA. A new graphical method for Pinch Analysis applications: Heat exchanger network retrofit and energy integration. Energy. 2015;81:159-174.

12. Bonhivers JC, Moussavi A, Alva-Argaez A, Stuart PR. Linking pinch analysis and bridge analysis to save energy by heat-exchanger network retrofit. Appl Therm Eng. 2016;106:443-472.

13. Floudas CA, Ciric AR, Grossmann IE. Automatic synthesis of optimum heat exchanger network configurations. AIChE J. 1986;32(2):276-290.

14. Akman U, Uygun K, Uzturk D, Konukman AES. HEN optimizations without using logarithmic-mean-temperature difference. AIChE J. 2002;48(3):596-606.

15. Silva ML, Zemp RJ. Retrofit of pressure drop constrained heat exchanger networks. Appl Therm Eng. 2000;20:1469-1480.

16. Bjork KM, Nordman R. Solving large-scale retrofit heat exchanger network synthesis problems with mathematical optimization methods. Chem Eng Proc. 2005;44:869-876.

17. Bochenek R, Jezowski JM. Genetic algorithms approach for retrofitting heat exchanger network with standard heat exchangers. Comput Aided Chem Eng. 2006;21:871-876.

18. Ponce JM, Serna M, Jimenez A. Heat exchanger network synthesis including detailed heat exchanger design using genetic algorithms. Ind Eng Chem Res. 2007;46:8767-8780.

19. Rezaei E, Shafiei S. Heat exchanger networks retrofit by coupling genetic algorithm with NLP and ILP methods. Comput Chem Eng. 2009;33:1451-1459.

20. Athier G, Floquet P, Pibouleau L, Domenech S. A mixed method for retrofitting heatexchanger networks. Comput Chem Eng. 1998;22:S505-S511.

21. Pan M, Bulatov I, Smith R. An efficient retrofitting approach for improving heat recovery in heat exchanger networks with heat transfer intensification. Ind Eng Chem Res. 2014;53(27):11107-11120.

22. Abbas HA, Wiggins GA, Lakshmanan R, Morton W. Heat exchanger network retrofit via constraint logic programming. Comput Chem Eng. 1999;23(99):S129-S132.

23. Pan M, Bulatov I, Smith R. New MILP-based iterative approach for retrofitting heat exchanger networks with conventional network structure modifications. Chem Eng Sci. 2013;104:498-524.

24. Nguyen DQ, Barbaro A, Vipanurat N, Bagajewicz MJ. All-at-once and step-wise detailed retrofit of heat exchanger networks using an MILP model. Ind Eng Chem Res. 2010;49:6080-6103.

25. Pan M, Bulatov I, Smith R. Exploiting tube inserts to intensify heat transfer for the retrofit of heat exchanger networks with considering fouling mitigation. Ind Eng Chem Res. 2013;52:2925-2943.

26. Pan M, Smith R, Bulatov I. A novel optimization approach of improving energy recovery in retrofitting heat exchanger network with exchanger details. Energy. 2013;57:188-200.

27. Sreepathi BK, Rangaiah GP. Improved heat exchanger network retrofitting using exchanger reassignment strategies and multi-objective optimization. Energy. 2014;67:584-594.

28. Sreepathi BK, Rangaiah GP. Retrofitting of heat exchanger networks involving streams with variable heat capacity: Application of single and multi-objective optimization. Appl Therm Eng. 2015;75:677-684.

29. Escobar M, Trierweiler JO, Grossmann IE. SynFlex: A computational framework for synthesis of flexible heat exchanger networks. Comput. Aided Chem. Eng. 2011;29:19241928.

30. Yee TF, Grossmann IE. Simultaneous optimization models for heat integration II. Heat exchanger network synthesis. Comput. Chem. Eng. 1990;14(10):1165-1184.

31. Escobar M, Trierweiler JO, Grossmann IE. Simultaneous synthesis of heat exchanger 
networks with operability considerations: Flexibility and controllability. Comput. Chem. Eng. 2013;55:158-180.

32. Zhu XX, Nie XR. Pressure drop considerations for heat exchanger network graaroots design. Comput Chem Eng. 2002;26:1661-1676.

33. Frausto-Hernandez S, Rico-Ramirez V, Jimenez-Gutierrez A, Hernandez-Castro S. MINLP synthesis of heat exchanger networks considering pressure drop effects. Comput Chem Eng. 2003;27:1143-1152.

34. Sorsak A, Kravanja Z. MINLP retrofit of heat exchanger networks comprising different exchanger types. Comput Chem Eng. 2004;28:235-251.

35. Kralj AK. Optimization of an industrial retrofitted heat exchanger network using a stagewise model. Energy. 2010;35:4748-4753.

36. Smith R, Pan M., Bulatov I. Chapter 32 Heat transfer enhancement in heat exchanger networks. In: Klemeš JJ. (editor). Handbook of Process Integration (PI): Minimisation of energy and water use, waste and emissions, Cambridge (UK): Woodhead/Elsevier; 2013.

37. Ciric AR, Floudas CA. A retrofit approach for heat exchanger networks. Comput Chem Eng. 1989;13(6):703-715.

38. Serth RW. Chapter 5 Design of shell-and-tube heat exchangers. In: Serth RW, (editor). Handbook of process heat transfer principles and applications. Elsevier Ltd.; 2007.

39. Cal Gavin Ltd. hiTRAN ${ }^{\circledR}$ thermal systems: changing fluid dynamics and harnessing the benefits. Tech. report of Cal Gavin Ltd. 2009. 


\section{List of figures}

Figure 1. The illustration of using the proposed approach for HEN retrofitting.

Figure 2. The motivation example (in simplification assumptions) and the retrofitted HEN solved by the existing approach 9

Figure 3. The motivation example (in complex situations) and the retrofitted HENs solved by our new approach

Figure 4. The illustration of temperatures addressed in the new HEN retrofit model.

Figure 5. The illustration of stream bypassing for an exchanger (hot fluid in shell side and cold fluid in tube side)

Figure 6. The illustration of parallel exchangers

Figure 7. The procedure of the two loops for the iteration optimisation algorithm

Figure 8. The original and the retrofitted HENs for large-scale example 